\title{
Genome-wide identification and characterization of the SBP-box gene family in Petunia
}

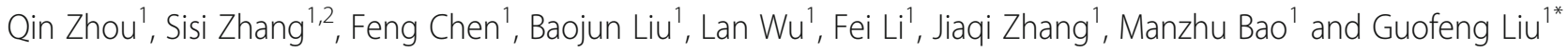

\begin{abstract}
Background: SQUAMOSA PROMOTER BINDING PROTEIN (SBP)-box genes encode a family of plant-specific transcription factors (TFs) that play important roles in many growth and development processes including phase transition, leaf initiation, shoot and inflorescence branching, fruit development and ripening etc. The SBP-box gene family has been identified and characterized in many species, but has not been well studied in Petunia, an important ornamental genus.
\end{abstract}

Results: We identified 21 putative SPL genes of Petunia axillaris and $P$. inflata from the reference genome of $P$. axillaris $N$ and $P$. inflata S6, respectively, which were supported by the transcriptome data. For further confirmation, all the 21 genes were also cloned from P. hybrida line W115 (Mitchel diploid). Phylogenetic analysis based on the highly conserved SBP domains arranged PhSPLs in eight groups, analogous to those from Arabidopsis and tomato. Furthermore, the Petunia SPL genes had similar exon-intron structure and the deduced proteins contained very similar conserved motifs within the same subgroup. Out of 21 PhSPL genes, fourteen were predicted to be potential targets of PhmiR156/157, and the putative miR156/157 response elements (MREs) were located in the coding region of group IV, V, VII and VIII genes, but in the 3'-UTR regions of group VI genes. SPL genes were also identified from another two wild Petunia species, P. integrifolia and $P$. exserta, based on their transcriptome databases to investigate the origin of PhSPLS. Phylogenetic analysis and multiple alignments of the coding sequences of PhSPLs and their orthologs from wild species indicated that PhSPLs were originated mainly from P. axillaris. qRT-PCR analysis demonstrated differential spatiotemperal expression patterns of PhSPL genes in petunia and many were expressed predominantly in the axillary buds and/or inflorescences. In addition, overexpression of PhSPL9a and PhSPL9b in Arabidopsis suggested that these genes play a conserved role in promoting the vegetative-to-reproductive phase transition.

Conclusion: Petunia genome contains at least 21 SPL genes, and most of the genes are expressed in different tissues. The PhSPL genes may play conserved and diverse roles in plant growth and development, including flowering regulation, leaf initiation, axillary bud and inflorescence development. This work provides a comprehensive understanding of the SBP-box gene family in Petunia and lays a significant foundation for future studies on the function and evolution of $S P L$ genes in petunia.

Keywords: Petunia, SPL genes, Transcription factor, Expression patterns, miR156/miR157, Flowering

\footnotetext{
* Correspondence: gfliu@mail.hzau.edu.cn

'Key Laboratory of Horticultural Plant Biology, Ministry of Education; Key Laboratory of Urban Agriculture in Central China, Ministry of Agriculture; College of Horticulture and Forestry Sciences, Huazhong Agricultural University, Shizishan Street No. 1, Wuhan 430070, China

Full list of author information is available at the end of the article
}

(c) The Author(s). 2018 Open Access This article is distributed under the terms of the Creative Commons Attribution 4.0 International License (http://creativecommons.org/licenses/by/4.0/), which permits unrestricted use, distribution, and reproduction in any medium, provided you give appropriate credit to the original author(s) and the source, provide a link to the Creative Commons license, and indicate if changes were made. The Creative Commons Public Domain Dedication waiver (http://creativecommons.org/publicdomain/zero/1.0/) applies to the data made available in this article, unless otherwise stated. 


\section{Background}

Transcription factors (TFs) are essential for the regulation of precise and coordinate gene expression via activating and/or repressing transcription in response to various endogenous and environmental signals, which plays crucial roles in the regulation of gene networks for many important developmental processes and defense responses in plants. TFs are usually classified into different families based on the sequence of DNA-binding domains and other conserved motifs [1]. SQUAMOSA PROMOTER BINDING PROTEIN (SBP)-box genes encode a family of plant-specific TFs that contain a highly conserved DNAbinding domain of 76 amino acids called the SBP domain $[2,3]$, which can form two tandem zinc fingers (Cys-CysHis-Cys and Cys-Cys-Cys-His), and possesses a nuclear localization signal (NLS) at the C-terminus partially overlapping with the second zinc finger $[4,5]$. The SBP domain is involved in both nuclear import and binding to a consensus DNA sequence with a GTAC core motif and gene-specific flanking regions $[6,7]$.

AmSBP1 and AmSBP2 are the first SBP-domain proteins discovered in plants, which were isolated from Antirrhinum majus in an in vitro approach and named after their binding ability to the promoter of the floral meristem identity gene SQUAMOSA [2]. Since then, SBP-box genes have been found in diverse plant species, including single-celled green algae, mosses, gymnosperms, and angiosperms [8]. Furthermore, genome-wide identified and analysis of the whole gene family were reported recently in some species, such as Arabidopsis [9, 10], rice [3], tomato [11], grape [12], apple [13], castor bean [14], Populus [15], Citrus [16], Gossypium [17], pepper [18], tobacco [19], oilseed rape [20], soybean [21], and moso bamboo [22]. In Arabidopsis, there are 16 SBP-LIKE (SPL) genes, which can be categorized into eight clades based on the amino acid sequence of their conserved SBP domain: AtSPL1/12/14/16, AtSPL2/ 10/11, AtSPL3/4/5, AtSPL6, AtSPL7, AtSPL8, AtSPL9/15, and AtSPL13 [3, 8]. Among them, ten genes from five clades (AtSPL2/10/11, AtSPL3/4/5, AtSPL6, AtSPL9/15 and AtSPL13) are targeted by miR156 [3, 23], an evolutionarily highly conserved miRNA in plants that plays master function of regulating the transition from the juvenile to the adult phase of vegetative development (vegetative phase change) $[24,25]$.

SPL genes control many aspects of plant development and physiology, including the vegetative phase change, flowering time, leaf initiation, shoot and inflorescence branching, fruit development and ripening, floral organ development and fertility, pollen sac development, trichome development, root development, and stress responses $[8,9,26-28]$. Recent studies provide a detailed picture of the function of miR156-targeted SPL genes in Arabidopsis: AtSPL2/9/10/11/13/15 contribute to both the juvenile-toadult phase transition (vegetative phase change) and the vegetative-to-reproductive phase transition (reproductive phase change or flowering), with AtSPL9/13/15 being more important than SPL2/10/11 [9]; AtSPL3/4/5 were previously reported to redundantly promote flowering through direct activation of LEAFY (LFY), FRUITFUL (FUL), and APETALA1 (AP1) [29], and they may act synergistically with the FLOWERING LOCUS T (FT)-FD module to induce flowering under long-day (LD) condition [30], whereas a recent study suggested that AtSPL3/4/5 don't play a major role in vegetative phase change or flowering, but promote the floral meristem identity transition [9]; AtSPL6 does not have a major function in vegetative morphogenesis [9], it can positively regulate a subset of defense genes, however, and plays a role in effector-triggered immunity [31]. Among the miR156 non-targeted SPL genes, AtSPL7 is a central regulator of copper $(\mathrm{Cu})$ homeostasis and play a major role in cadmium $(\mathrm{Cd})$ response $[32,33]$. AtSPL8 was found to be a tissue-dependent regulator in GA signaling and regulate early anther development and gynoecium differential patterning in concert with multiple miR156 targeted SPL genes, as well as trichome formation on sepals, stamen filament elongation, and root growth [34-37]. AtSPL14 gene may function to delay phase transition [38].

Studies in other species revealed that SPL genes underwent an extensive neofunctionalization during their evolution. For instance, the maize TEOSINTE GLUME ARCHITECTURE1 (tga1) gene, an AtSPL13 homolog, controls glume development [39]. The rice TGA1 ortholog GW8/OsSPL16 gene controls grain size, shape and quality [40, 41]. The maize LIGULELESS1 (LG1) gene (closest to AtSPL8) and its ortholog in rice (OsLG1) were found to control the formation of the ligule and auricule [42, 43]. Recently, they were found to also control the branch angle of tassel and panicle, respectively [44-46]. The tomato Colorless non-ripening ( $\mathrm{Cnr}$ ) locus encode an AtSPL3 ortholog and is essential for fruit ripening [47].

Petunia (Petunia hybrida) is a popular and important ornamental species belonging to the economically important family Solanaceae that has been used as a genetic model system for a long history [48]. Petunia is also a good model for comparative research of gene function become of its many advantages, including the evolutionary position of asterid, ease of cultivation and propagation, highly efficient genetics and transformation. However, our knowledge on the evolution and function of SBP-box gene family in petunia is very limited yet. Only one recent study functionally characterized two petunia SPL genes, PhSBP1 and PhSBP2, which showed that they have overlapping but divergent functions in the reproductive transition and leaf initiation rate [49]. Recently, the whole-genome sequencing was achieved for inbred derivatives of two wild Petunia species, $P$. axillaris $\mathrm{N}$ and $P$. inflata S6 [50], which provides a good opportunity to study the important gene 
family of TFs on a genome-wide scale. P. hybrida was considered to be originated from the hybridization of two biological species, one with erect habit and white flowers ( $P$. axillaris), and the other with decumbent stems and purple flowers (P. integrifolia). P. inflata was previously considered as a synonym of $P$. integrifolia, and subsequently as a subspecies under $P$. integrifolia (P. integrifolia Subs $p$. inflata), but a recent study accepted it as distinct from $P$. integrifolia with the unfolded and straight calyx lobes as useful diagnostic characters [51]. Here, we report a genome- and transcriptome-wide analysis of the SBP-box gene family in Petunia, including $P$. axillaris, $P$. inflata, $P$. integrifolia, $P$. hybrida, and $P$. exserta, a unique species in the genus, with red corolla and distinct exserted stamens and stigma. Based on genome and transcriptome scanning, 21 SBP-box genes were identified in $P$. axillaris and $P$. inflata, respectively, confirmed by cloning from $P$. hybrida line W115. The gene structure, phylogeny, motif composition, miRNA target site and expression pattern in various tissues were systematically analyzed. In addition, the function of two representative genes, PhSPL9a and PhSPL9b, was characterized in transgenic Arabidopsis plants. The data presented here provide good foundation for understanding the key roles of SPL genes in petunia development and other biological processes.

\section{Results}

\section{Identification of Petunia SPL genes}

The SPLS of Arabidopsis, tomato and tobacco were used to search the genome and transcriptome datasets of $P$. axillaris and $P$. inflata $[50,52]$, which identified 21 putative SPL genes in the two species, designated as PaSPLs and PiSPLs (Additional files 1 and 2), respectively. To validate the full-length open reading frame (ORF) sequences and predicted exon-intron structures of the Petunia SPL genes, the coding sequence of PhSPL genes (PhSPLs) were cloned by RT-PCR from P. hybrida line W115. As a result, all $21 S P L$ genes were isolated successfully from W115 and confirmed by sequencing. We named these genes according to the closest homologs of them in Arabidopsis (Table 1).

\section{Phylogenetic analysis of SPL proteins from petunia, tomato, and Arabidopsis}

To figure out the evolutionary relationship of PhSPLs, an unrooted phylogenetic tree was constructed using the highly conserved SBP-domains (76 aa, Fig. 1) of 21 petunia SPL proteins (PhSPLs), 16 Arabidopsis SPL proteins (AtSPLs) and 15 tomato SPL proteins (SlySBPs) by the maximum likelihood algorithm in MEGA 6.0, which demonstrated that 21 petunia SPL proteins were clustered into eight groups (Group I to Group VIII), and each group contained at least one member from Arabidopsis and
Table 1 Nomenclature of SPL genes in Petunia hybrida line W115 (Mitchel diploid)

\begin{tabular}{llll}
\hline Gene name & Accession number & Preston et al. [49] & CDS length (bp) \\
\hline PhSPL2 & MF580469 & 1404 \\
PhCNR & MF580470 & PhCNR & 285 \\
PhSPL3 & MF580471 & PhSBP1 & 423 \\
PhSPL4a & MF580472 & 420 \\
PhSPL4b & MF580473 & 636 \\
PhSPL4C & MF580474 & PhSBP2 & 537 \\
PhSPL6a & MF580475 & 1575 \\
PhSPL6b & MF580476 & 1491 \\
PhSPL6C & MF580477 & 1563 \\
PhSPL6d & MF580478 & 1539 \\
PhSPL6e & MF580479 & 1527 \\
PhSPL7 & MF580480 & 2406 \\
PhSPL8 & MF580481 & 915 \\
PhSPL9a & MF580482 & 1164 \\
PhSPL9b & MF580483 & 1125 \\
PhSPL9C & MF580484 & 1146 \\
PhSPL12a & MF580485 & 3021 \\
PhSPL12b & MF580486 & 2958 \\
PhSPL12C & MF580487 & 2910 \\
PhSPL12d & MF580488 & 3027 \\
PhSPL13 & MF580489 & 990 \\
\hline
\end{tabular}

tomato (Fig. 2). The Group I and Group VII contained only one SPL from petunia, Arabidopsis and tomato (PhSPL7, AtSPL7 and SlySBP7 in Group I; PhSPL13, AtSPL13 and SlySBP13 in Group VII), respectively, suggesting potential functional conservation of SPL7 and SPL13 genes in plants. The Group II consisted of four petunia SPLs (PhSPL12a to PhSPL12d), four Arabidopsis SPLs (AtSPL1, AtSPL12, AtSPL14 and AtSPL16), and two tomato SPLs (SlySBP12a and SlySBP12b). The Group III contained also only one SPL in petunia (PhSPL8) and Arabidopsis (AtSPL8), but two in tomato (SlySBP8a and SlySBP8b). The Group IV contained five petunia SPLs (PhSPL6a to PhSPL6e), three tomato SPLs (SlySBP6a to SlySBP6c), but only one Arabidopsis genes (AtSPL6), suggesting the fast gene duplication of SPL6 clade in petunia and even in Solanaceae family. The Group V consisted of three Arabidopsis SPLs (AtSPL2, AtSPL10 and AtSPL11), two tomato SPLs (SlySBP2 and SlySBP10) and one petunia SPL (PhSPL2). PhCNR, PhSPL3, and PhSPL4a/ b/c were clustered in Group VI, and PhSPL9a, PhSPL9b and PhSPL9c belong to Group VIII. The recognition of these different protein groups was reflected in their different gene length and genomic intron-exon structures (Fig. 3). 


\section{SBP domain}

\begin{tabular}{|c|c|}
\hline SPL2 & SRFHSLSEFDEKKRSCRRRL \\
\hline PhCNR & \\
\hline SPL3 & SRFHLLAEFDEAKRSCRRRLAGHNERRRKS \\
\hline SPL $4 a$ & RFHELGEFDESKRSCRRRLAGHNERRRK. \\
\hline PhSPL4b & RFHELTEFDESKRSCRRRLAGHNERRRKI \\
\hline PhSPL $4 \mathrm{C}$ & DCREHELSEFDGTKRSCRRRLAGHNERRRKT \\
\hline hSPL6a & ÖCSRFHLLAEFDEGKRSCRKRLAGHNERRRKE \\
\hline SPL $6 \mathrm{~b}$ & ÖCSRFHLLGAFDEGKRSCRKRLAGHNERRRKP \\
\hline PhSPL6c & OCSRFHLLGDFDDGKRSCRKRLAGHNERRRKS \\
\hline PhSPL6d & LAEFDDGKRSCRKRLAGHNERRRKE \\
\hline SPL6e & VHSKTAKVIVNGIEQR \\
\hline SPL7 & GKFHILSDFDEGKRSCRRK \\
\hline PhSPL8 & CSRFHLLSEFDNGKRSCRKRLADHNRRRRKN \\
\hline PhSPL9a & THSKSPVVIVAGIEQR \\
\hline PhSPL9b & MHSKSPTVVVGGLEQR \\
\hline PhSPL9c & EMHAKAPKVVLLGLEOR \\
\hline PhSPL12a & QCSRFHALQEFDEGKRSCRRRLAGHNKRRRKT \\
\hline PhSPL12b & DVHSKAAKALVGNVMOR \\
\hline & MMHSKATTALVANVMQI \\
\hline PhSPL12d & DVHSKAVSALVGNVMQR \\
\hline PhSPL13 & DCSRFHSLVEFDDGKRSCRKRLDGHNRRRRKP \\
\hline CNR & FHSKSPIVLISGLQKF \\
\hline BP2 & IIHSKCPKVIILGRHR \\
\hline BP3 & FHAKAPEVLIDGLRQR \\
\hline SlysBP4 & OCSRFHELTEFDESKRSCRRRLAGHNERRRKS \\
\hline P6a & EVHSKTAKVIVNGIEQR \\
\hline 66 & NEHSKTAIVIVNGIEQR \\
\hline $3 \mathrm{P} 6 \mathrm{c}$ & CSREHLLAEFDDGKRSCRKRLAGHNERRRKE \\
\hline SlySBP7 & CGKFH ILSDFDEGKRSCRRKLERHNNRRRRK \\
\hline $\mathrm{Sl}$ & Q̈CSRFHL \\
\hline $\mathrm{P} 8 \mathrm{~b}$ & EFHSKASTVIAAGLTQF \\
\hline $\mathrm{P} 10$ & CSRFHSVSEFDDKKRSCRRRLSDHNARRRKE \\
\hline SlySBP12a & CSRFHALQEFDEGKRSCRRRLAGHNKRRRKT \\
\hline $12 \mathrm{~b}$ & OCSRE! \\
\hline Sly & QCSRFHSLVEFDDGKRS \\
\hline SlySBP15 & CSRFHQLTEFDQGKRSCRRRLACHNERRRKP \\
\hline AtSPL1 & QCSRFHLLQEFDEGKRSCRRRLAGHNKRRRKT \\
\hline & OCSR \\
\hline & FHAKAPHVRISC \\
\hline & 2QCSRFHDLQEFDEAKRSCRRRLAGHNERRRKS \\
\hline AtSPL5 & 20 CSRFHELPEFDEAKRSCRRRLAGHNERRRKI \\
\hline & DSREHFLSEF \\
\hline & RCATASFVVLDGENKF \\
\hline AtSPL8 & QQCSRFHLLSEFDNGKRSCRKRLADHNRRRRKC \\
\hline AtSPL9 & QCSRFHQLPEFDLEKRSCRRRLAGHNERRRKP \\
\hline & 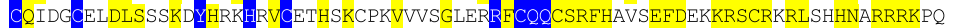 \\
\hline & UUGUCDUUCUSCT \\
\hline Ats: & EQCSRFHVLEEFDEGKRSC \\
\hline AtSPL13 & CQQCSRFHALEEFDEGKRSCRKRLDGHNRRRRKP \\
\hline & COCSREHLLSEFDEGKRSCRRRLAGHNRRRRKT \\
\hline & CQQCSRFHQLSEFDLEKRSCRRRLACHNERRRKP \\
\hline & REHLLSEFDEGKRSCRRRLDGHNRRRRKT \\
\hline
\end{tabular}

Fig. 1 Multiple alignments of the highly conserved SBP-domains. Multiple alignments of the highly conserved SBP-domains (76 aa) of 21 PhSPL proteins, 15 SlySBP proteins, and 15 AtSPL proteins. The conserved SBP domain included 2 Zn-finger structures and NLS

Sequence feature and gene structure of Petunia SPL genes Sequence feature analysis indicated that the length of Petunia SPL genes varied from 1024 bp (PaSPL4c) to 9487 bp (PaSPL7) in P. axillaris (Additional file 1) and 1133 bp (PiSPL4C) to 9350 bp (PiSPL7) in P. inflata (Additional file 2). The ORF length of PhSPLs varied from $285 \mathrm{bp}(P h C N R)$ to $3027 \mathrm{bp}(P h S P L 12 d)$; the size of deduced PhSPL proteins varied between 94 and 1008 amino acids (Table 1). Gene structure analysis showed that the number of exon was diverse in different groups, but was nearly consistent in the same group, such as genes in Group VI (SPL3 and SPL4a/b/c) have two exons, genes in Group IV (SPL6a to SPL6e) contain 3 exons, with the exception of PaSPL6c that seems have lost the second exon, whereas genes in Group I (SPL7) and Group II (SPL12a to SPL12d) possess 10-11 exons (Fig. 3, Additional files 1 and 2). All Petunia SPL genes were found to have an intron at an evolutionary highly conserved position in the SBP domain, although its length varied greatly among the members from the shortest 117 bp in PiSPL2 to the longest 4396 bp in PiSPL9a.

\section{Origin of PhSPL genes}

To understand the origin of $P h S P L$ genes, the coding sequences of PhSPLs were used to query the Transcriptome Shotgun Assembly (TSA) database in NCBI of another two wild Petunia species, P. integrifolia and P. exserta [52]. Finally, nineteen SPL genes were recognized in $P$. integrifolia (designated as PintSPLs, Additional file 2) and P. exserta (designated as PeSPLs, Additional file 3), respectively. To 


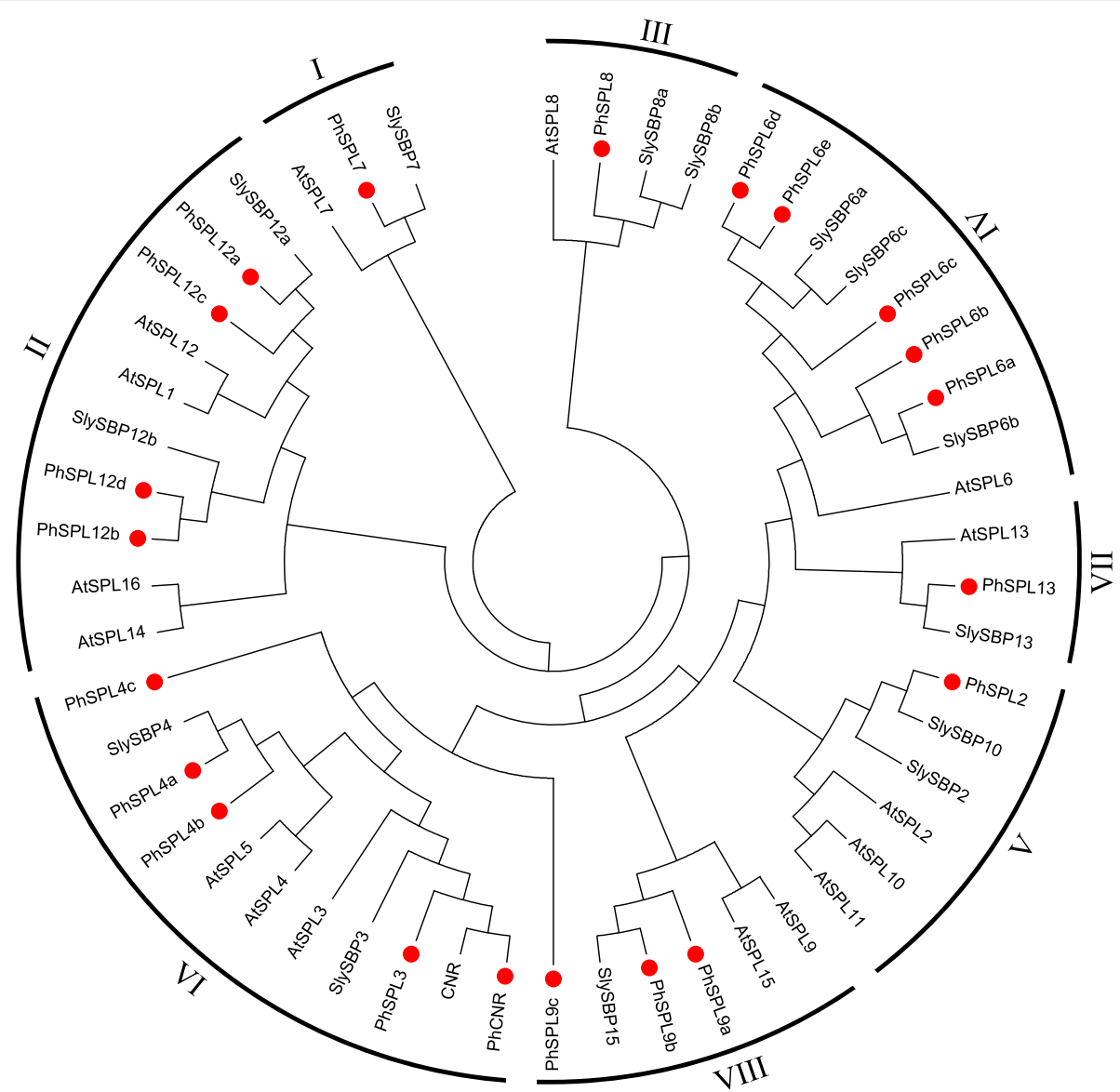

Fig. 2 Phylogenetic tree based on the conserved SBP domains. Phylogenetic tree based on the conserved SBP domains (76aa) alignment of 21 PhSPL predicted proteins, 16 AtSPL proteins and 15 SlySBP proteins. The tree was generated with MEGA v6.0 software, using the maximum likelihood (ML) method, and bootstrap values were calculated with 500 replicates. Groups defined were shown on the outside of the circle [11]

elucidate whether $P$. axillaris, $P$. inflata, $P$. integrifolia or $P$. exserta is the donor of PhSPL genes in hybrid petunia, multiple alignments of the nucleotide sequences (CDS region) of PhSPLs, PaSPLs, PiSPLs, PintSPLs and PeSPLs was conducted, and then a phylogenetic tree was constructed by the Neighbor-Joining (NJ) method. The phylogenetic analysis showed that 17 of $21 P h S P L$ genes, including PhSPL2, PhCNR, PhSPL3, PhSPL4a/b, PhSPL6a, PhSPL6c/ $d / e, P h S P L 7, P h S P L 9 a / b / c$, and PhSPL12a/b/c/d, were clustered together with their orthologs from $P$. axillaris, and three PhSPLs (PhSPL4c, PhSPL6b and PhSPL8) were grouped together with the orthologs of $P$. exserta. Interestingly, only one PhSPLs (PhSPL13) were grouped together with the orthologs of $P$. integrifolia, and no PhSPL gene was clustered together with the orthologs from $P$. inflata (Fig. 4), implying that most PhSPL genes might be derived from $P$. axillaris or $P$. exserta.

To further confirmed the relationship of these SPL genes, the coding sequences of orthologs from P. hybrida W115, $P$. axillaris, $P$. integrifolia, $P$. inflata and $P$. exserta, respectively, were aligned and compared for each member. The results showed that the coding sequences of $P h C N R$, PhSPL3, PhSPL6a, PhSPL6d, PhSPL7 and PhSPL12a/b/c were exactly the same as that of the orthologs from $P$. axillaris, but different at least for two nucleotides from that of the orthologs in P. inflata, P. integrifolia and $P$. exserta (Additional file 4), indicating that these genes are originated from $P$. axillaris; the coding sequences of PhSPL4c was identical to that of PeSPL4c, indicating it was most probably originated from $P$. exserta. PhSPL6b as well as PhSPL8 showed few (1 or 2) and same number of nucleotide differences compared to the orthologs of $P$. axillaris and $P$. exserta, but with more changes (23 and 13/11 nucleotides, respectively) in comparison to PiSPL6 $b$ and PiSPL8/PintSPL8, and the differential 1-2 nucleotides are also different from that of PiSPL6b and PiSPL8/PintSPL8, suggesting PhSPL6b and PhSPL8 were derived from $P$. axillaris or $P$. exserta (the coding sequences of PaSPL6b and PeSPL6 $b$ as well as PaSPL8 and PeSPL8 are identical). For the rest of PhSPLs except PhSPL6c and PhSPL13, also only few (1-8) nucleotides are different when compared with PaSPLs, while when compared with PiSPLs, PintSPLs 


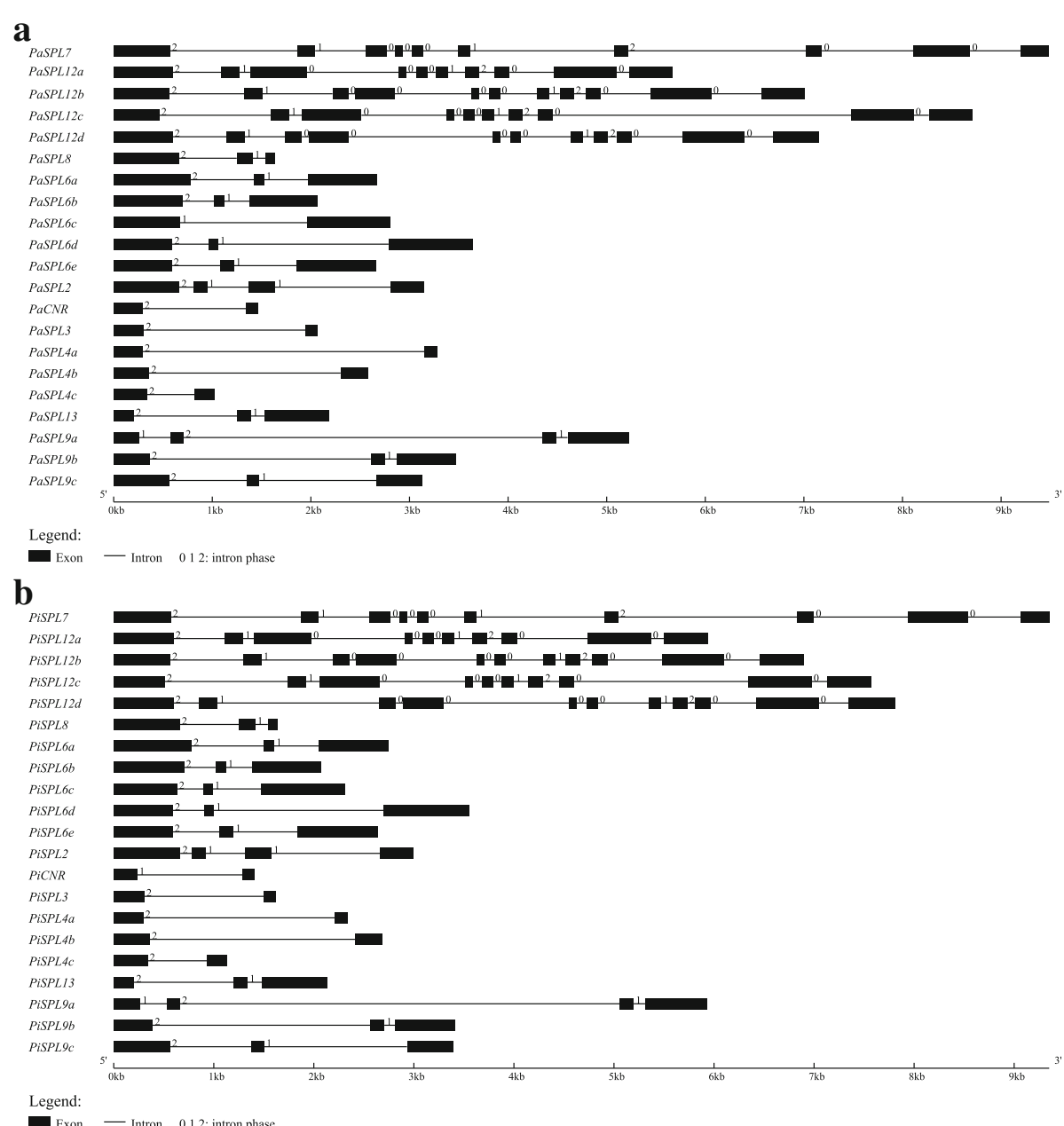

Fig. 3 Intron-exon structures of PaSPL and PiSPL genes. a, Intron-exon structures of PaSPLs. b, Intron-exon structures of PiSPLS. 5'UTR and 3'UTR were not showed, the exons and intron were indicated by black block and gray thin line, respectively. The 0, 1 and 2 represented intron phases

and PeSPLs, especially the sequences from PiSPLs and PintSPLs, more nucleotide and amino acid changes were found (Additional file 4). Further inspection of the differential nucleotides showed that changed nucleotides in PhSPL4a, PhSPL6e, and PhSPL12d are also different from the genes of $P$. inflata, $P$. integrifolia and $P$. exserta, suggesting they may be derived from $P$. axillaris or originated from other relatives; in PhSPL4b, the varied 3 nucleotides are located in the latter part of the coding sequence that is identical to the sequence of PeSPL4b, indicating it may be derived from the recombination of PaSPL $4 b$ and PeSPL4b, i.e. a hybrid origin of $P$. axillaris and P. exserta; in PhSPL2 and $P h S P L 9 a / b / c$, some of the varied nucleotides are identical to the sequences of $P$. inflata, $P$. integrifolia and/or $P$. exserta orthologs, while the others are different from the genes of all four species, suggesting these members may also have a hybrid origin between PhSPLs and PeSPLs or PiSPLs/PintSPLs. PhSPL13, however, showed fewer nucleotide changes compared to PeSPL13 and PintSPL13 than to PaSPL13, and 3 of 4 different nucleotides between PhSPL13 and PeSPL13 are identical to the sequences of PintSPL13 and PaSPL13, while the other one is PhSPL13specific, indicating it may be derived from the recombination of PeSPL13 and PintSPL13 or PaSPL13. As for PhSPL6c, it is strange that its coding sequence was almost identical (only one nucleotide variation) to that of PaSPL6c (accession number: GBRU01020485.1) from the transcriptome database of $P$. axillaris [52], but the PaSPL6c gene identified in the genome of $P$. axillaris $\mathrm{N}$ [50] showed an extended first exon (635 to $670 \mathrm{bp}$ ) and loss of the second exon ( $89 \mathrm{bp}$ ), so resulting in 66 nucleotide changes between PhSPL6c and the PaSPL6c identified from the genome, which was confirmed by our recent transcriptome data of $P$. axillaris $\mathrm{N}$ [53]. Excluding the extended and lost sequences of the genome PaSPL6c, the rest part of coding sequence was identical to that of PhSPL6c, suggesting PhSPL6c should also be derived from $P$. axillaris. 


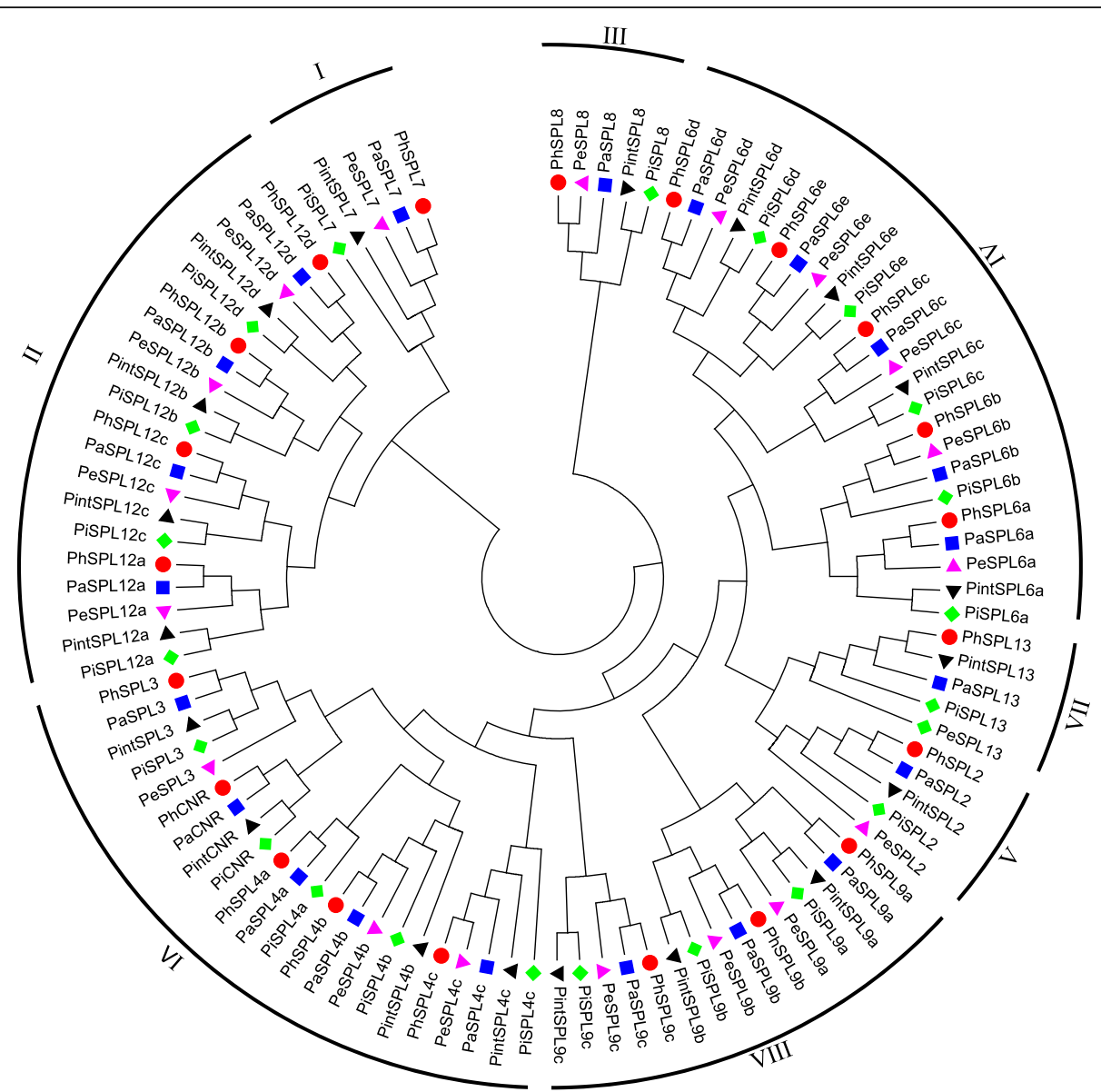

Fig. 4 Phylogenetic tree based on the cDNA sequence alignment of PhSPLs, PaSPLS, PiSPLs, PintSPLs and PeSPLs. PaSPL, the SPL genes of P. axillaris. PiSPL, the SPL genes from $P$. inflata. PintSPL, the SPL genes from $P$. intergrifolia. PeSPL, the SPL genes from $P$. exserta. The tree was generated with MEGA v6.0 software using the Neighbor-Joining (NJ) method and 1000 bootstrap replicates

\section{Conserved domains and motifs of PhSPL proteins}

The identified 21 PhSPL proteins were analyzed for conserved domains using the Conserved Domain Database in NCBI, which showed that all PhSPL proteins contained the conserved SBP domain. Multiple alignments of the SBP domains demonstrated that all SBP domain of PhSPLs except that of PhCNR contained two zinc finger motifs, $\mathrm{Zn} 1$ (CCCH type) and Zn2 (CCHC type), and a C-terminal nuclear localization signal (NLS), like that in other plant species (Fig. 1). The PhCNR protein terminated at the beginning of $\mathrm{Zn} 2$, so lacking the second zinc finger motif and NLS. Furthermore, four PhSPLs (PhSPL12a to PhSPL12d) belong to Group II contained an ANK domain with two ankyrin repeats, which mediate proteinprotein interactions [54], and this is consistent with previous reports in other plants.

The MEME was used to analyze conserved and potential motifs in PhSPL protein sequences (Fig. 5, Additional file 5). The number of motifs in each PhSPL varies from 1 to 17 (Fig. 5). Three motifs (motif 1, 2 and 3) constitute the SBP domain, and are conserved in all PhSPLs except for PhCNR which lack motif 2 and 3. Motif 1 is located at the first $\mathrm{Zn}$ finger; Motif 2 and 3 present the second $\mathrm{Zn}$ finger and NLS, respectively. PhSPL12a/b/c/d (Group II) are the longest group of proteins and correspondingly possess maximum number of motifs as compared to other PhSPLs. For example, motif 4, 7-16, and 20 are all exclusively present in $\mathrm{PhSPL} 12 \mathrm{a} / \mathrm{b} / \mathrm{c} / \mathrm{d}$ proteins. Motif 5 was recognized in two members of Group II (PhSPL12b and PhSPL12d) and three members of Group IV (PhSPL6c/d/ e) proteins. Motif 6 was shared by all members of Group I (PhSPL7) and Group II (PhSPL12a-d) proteins. Motif 17 was only recognized in PhSPL6c, PhSPL6d and PhSPL6e. Motif 17 was found in all Group IV proteins (PhSPL6a-e) and two Group VIII proteins (PhSPL9a and PhSPL9b). Motif 19 was present specially in the Group IV members.

\section{PhSPLs targeted by miR156/157}

In order to understand the miR156-mediated posttranscriptional regulation of PhSPL genes, we searched the CDS and 3'-UTR sequences of all PhSPLs for target site identification of petunia miR156 and miR157. Previously, 


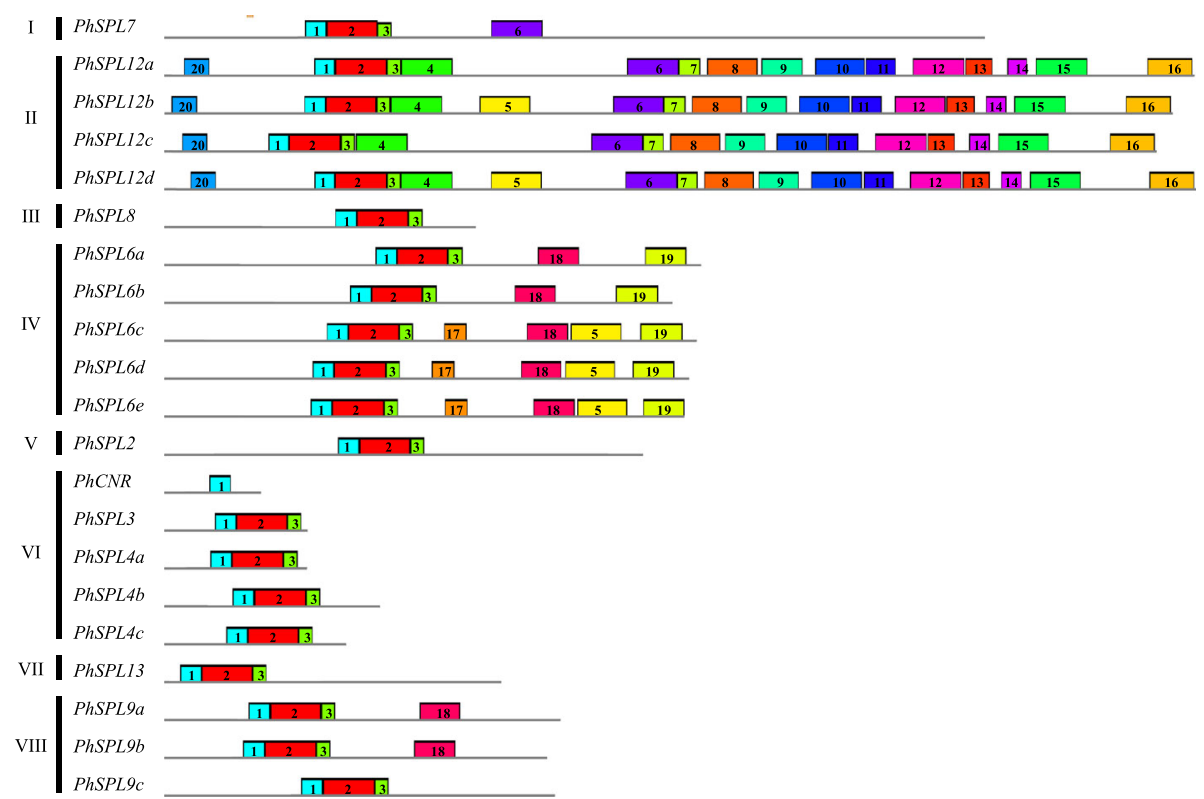

Fig. 5 The conserved and potential motifs in PhSPL protein sequences predicted by MEME

ten miR156 (miR0156a-g and miR0156j-l) and five miR157 (miR0157a-e) genes were identified from petunia genome, which produced three kinds of mature miRNA sequences (miR0156a-g, miR0156j-l and miR0157a-e) [50]. A comparison of the mature PhmiR156/157 sequences to PhSPLs transcript sequences showed that 14 out of $21 \mathrm{PhSPL}$ genes contained sequences complementary to the PhmiR156 or PhmiR157 mature sequences with one to two mismatches as maximum (Fig. 6), which suggests that PhmiR156/157 may specifically target these gene in petunia. These putative miR156/157 response elements (MREs) of PhSPL genes were located downstream of the SBP-box in the coding region of genes in groups IV (PhSPL6a-e), V (PhSPL2), VII (PhSPL13) and VIII $(P h S P L 9 a / b / c)$, while in the case of members in Group VI (PhSPL3 and PhSPL4a/b/c), it was present in the 3'-UTR regions.

\section{Expression patterns of PhSPL genes}

Transcription activity of PhSPL genes was investigated in various tissues using $\mathrm{qPCR}$ with gene-specific primers (Additional file 6). According to their expression patterns (Fig. 7, Additional file 7), PhSPL genes can be roughly classified into several groups. The first group was ubiquitiously expressed at relatively high levels in all tested tissues, such as PhSPL6a, PhSPL6b, PhSPL7, PhSPL12a, PhSPL12c and PhSPL12d. PhSPL6a and PhSPL12a showed the highest expression levels in most tissues among all PhSPL genes, with PhSPL6a expressed higher in axillary buds, flower buds, and roots than in other tissues, PhSPL12a expressed higher in axillary buds, inflorescences and flower buds than in other tissues (Fig. 7). PhSPL6b was expressed at significantly lower level (about 100 folds less) than PhSPL6a, with more expression in roots, inflorescences, and axillary buds than in other tissues. PhSPL7 showed the expression level of higher (about 10 folds more) than PhSPL6b, but lower (about 10 folds less) than PhSPL6a, with higher expression in axillary buds, inflorescences, flower buds and young fruits. PhSPL12c and PhSPL12d displayed comparable expression levels to the PhSPL7, but they have different expression pattern, for instance, PhSPL12c was expressed at the highest level in cotyledons, followed by inflorescences, while PhSPL12c showed highest expression in inflorescences with the lowest expression level in cotyledons. The second group had no expression or was expressed at very low levels in all tissues, such as PhSPL4a, PhSPL6e and PhSPL9b. No expression was detected for PhSPL4a in most tissues but very weak expression in inflorescences and cotyledons. PhSPL6e and PhSPL9b showed the expression levels less than millesimal of the first group genes, with PhSPL6e mainly expressed in axillary buds and bracts, and PhSPL9b mainly in roots, axillary buds and flower buds. The third group was expressed specially in some tissues, including PhSPL2, PhCNR, PhSPL3, PhSPL4b, PhSPL4c, PhSPL6c, PhSPL6d, PhSPL8, PhSPL9a, PhSPL9c, PhSPL12b, and PhSPL13. PhSPL2 and PhSPL13 were expressed in bracts and inflorescences. PhCNR and PhSPL3 were expressed mainly in axillary buds followed by inflorescences and flower buds, but the expression levels of $P h C N R$ were significantly lower than that of PhSPL3. PhSPL4b and PhSPL4c was expressed in most tissues including stems, leaves, axillary buds, inflorescences, flower buds and bracts, but almost no transcripts were detected in fruits, young seedlings and cotyledons. PhSPL6c and PhSPL6d were expressed mainly in axillary buds and inflorescences. PhSPL8 was 


PhSPL2
PhSPL3
PhSPL4a
PhSPL4b
PhSPL4c
PhSPL6a
PhSPL6b
PhSPL6c
PhSPL6d
PhSPL6e
PhSPL9a
PhSPL9b
PhSPL9C
PhSPL13
miR0156a-gRC
miR0156j-1RC
miR0157a-eRC
Consensus

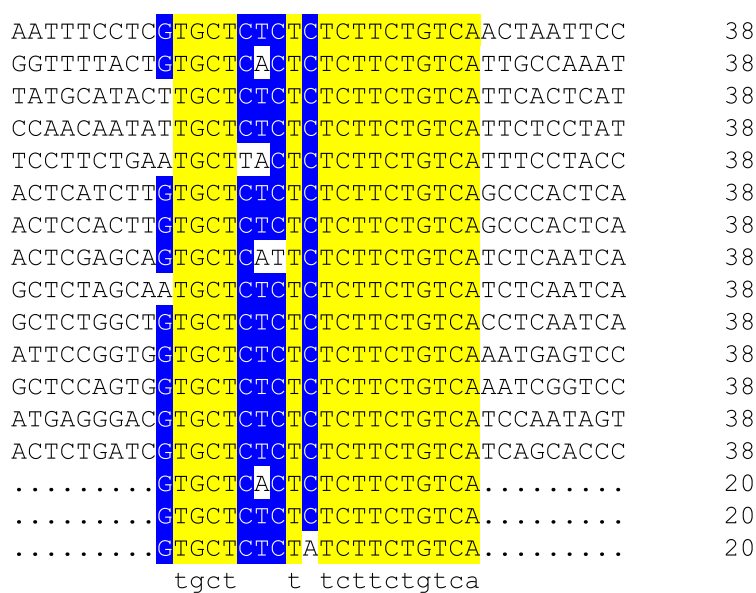

Fig. 6 Sequence alignment of petunia miR156/157 complementary sequences with the target sites in PhSPL genes. The target sites are located in the coding regions with the exception of PhSPL3, PhSPL4a, PhSPL4b and PhSPL4C where they are located in the 3'-UTR. RC, reverse complementary sequence of the mature petunia miR156/157

expressed mainly in inflorescences, flower buds and fruits. PhSPL9a, PhSPL9c and PhSPL12b showed similar expression patterns, with the highest expression level in inflorescences followed by axillary buds or flower buds.

\section{Overexpression of PhSPL9a and PhSPL9b in Arabidopsis}

To characterized the functions of PhSPL9a and PhSPL9b, two co-orthologs of AtSPL9 and AtSPL15, we constructed expression vectors 35S:PhSPL9a and 35S:PhSPL9b, then introduced into Arabidopsis. Fifty-two and thirty-five independent $\mathrm{T}_{1}$ transgenic lines were achieved for 35S:PhSPL9a and 35S:PhSPL9b, respectively. Twenty-eight and twentyone of $\mathrm{T}_{1}$ transgenic lines from 35S:PhSPL9a and 35S: PhSPL9b, respectively, showed earlier flowering than the empty pCAMBIA2300 plasmid transformed control plants $(\mathrm{CK})$. According to the phenotypic alterations, for each gene construction three $T_{1}$ transgenic lines whose progenies showed a 3:1 segregation ratio for kanamycin resistance, which may indicate a single-copy insertion of transgenes, were chosen for further experiment of. $32 \mathrm{~T}_{2}$ transgenic plants for each line were used to investigate the flowering time and floral phenotypes.

Under long day conditions, the control plants initiated flowering when average $12.7 \pm 0.8$ rosette leaves and $2.3 \pm$ 0.5 cauline leaves were produced (Additional file 8). In contrast, transgenic lines that exhibit severe phenotype such as PhSPL9a-4 bolted obviously earlier than CK, with significantly $(P<0.01)$ decreased number of rosette leaves and usually determinate inflorescence that terminated with a polygynoecial flower (Fig. 8b). Most transgenic lines of 35S:PhSPL9a and 35S:PhSPL9b showed moderate phenotypes, which bolted and flowered after producing nine to eleven rosette leaves (Fig. 8a, c; Additional file 8) under the same condition. However, there was no significant difference in the number of cauline leaf between the transgenic plants and CK.

RT-PCR analysis indicated that the phenotypic variations are related in a large extent to the expression levels of the transgenes, namely higher expression levels tend to result in more severe phenotypic changes such as earlier bolting and flowering time, and vice versa (Fig. 8d, e; Additional file 8).

\section{Discussion}

\section{Evolution of SPL genes in Petunia}

The SBP-box proteins (SPLs) constitute a family of transcription factors that play diverse roles in plant growth and development. Phylogenetic evidence indicated that SBP-box genes had underwent several ancient and more recent duplication events, resulted in the formation and retention of multiple SPL paralogs and clades [8]. Salinas et al. [11] reported eight (I-VIII) major SPL clades in plants based on a phylogenetic tree of 105 SPL protein sequences from seven species using the neighbor-joining (NJ) algorithm, at least four of which predate the diversification of land plants. A latter phylogenetic analysis with a slightly different dataset of SPL genes using the maximum likelihood (ML) method supported the eight major clades, and suggested a possible ninth clade containing OsSPL14/17 from rice and $Z m S B P 6 / 8$ from maize [8]. Recently, phylogenetic reconstruction with 104 full length SBP-box protein sequences from five species including moss, Arabidopsis, poplar, rice and maize demonstrated that the SBP-box genes form two lineages (group I and II) through an early duplication event, and the latter is further divided into two distinct subgroups (subgroup II-1 and II-2) caused by several rounds of duplication [55].

In this work, the SPL genes were identified from four Petunia species at genome or transcriptome scale, followed by cloning and sequencing of the orthologs from a hybrid 


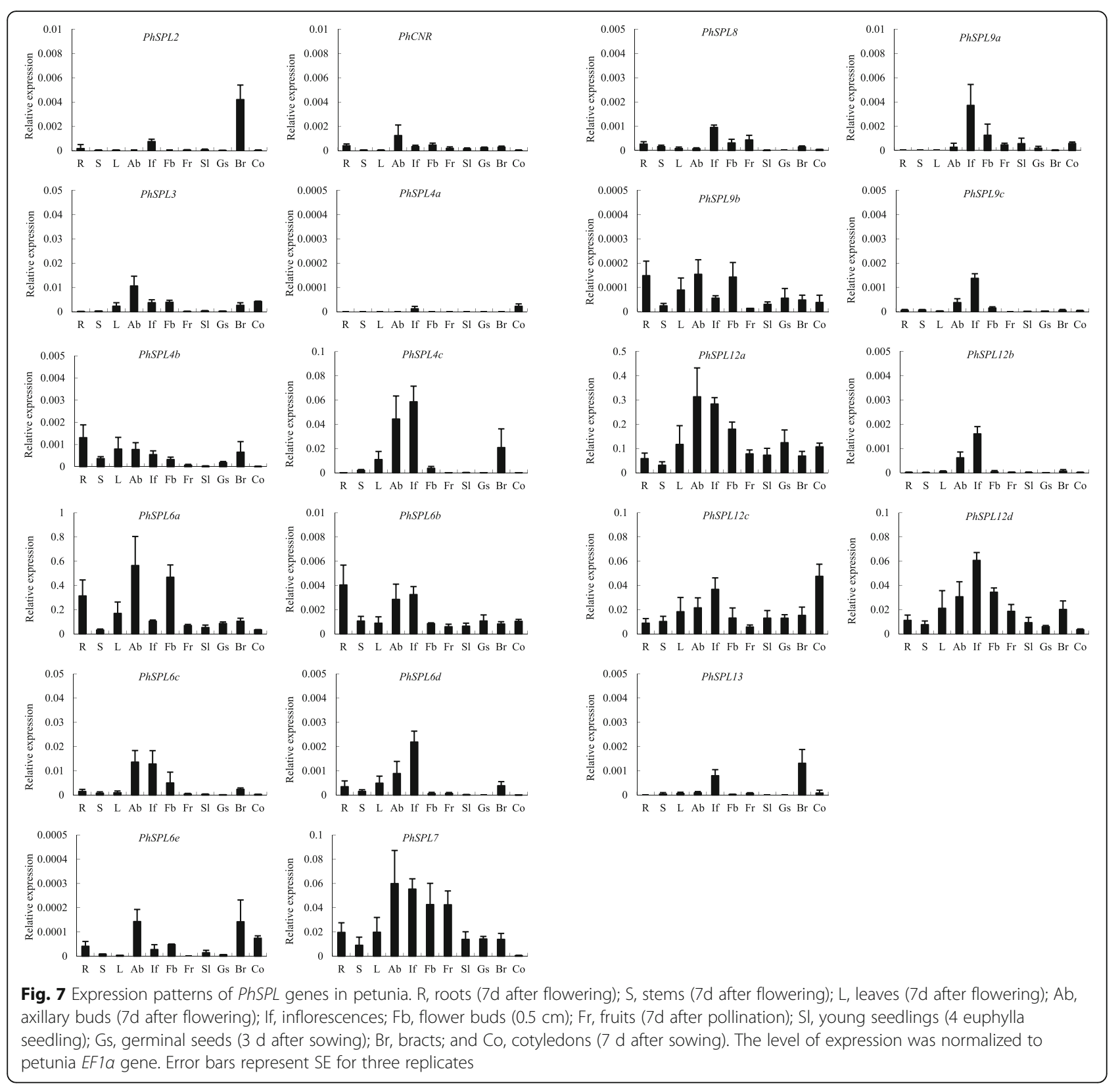

petunia line W115. As a result, 21 putative SPL genes were identified in the genome of $P$. axillaris (PaSPLS) and $P$. inflata (PiSPLS), respectively, 19 SPL genes were recognized from the transcriptome of $P$. integrifolia (PintSPLS) and $P$. exserta (PeSPLS), respectively, and 21 SPL genes were isolated from petunia line W115 (PhSPLs), a number similar to that found in Nicotiana tomentosiformis (Additional file 9), grape [12], rice [3], and Ziziphus jujuba [56]. However, in contrast to several other species in Solanaceae family, including tomato [11], pepper [18], and potato [57], Petunia appears to contain a larger number of SPL genes (21 vs. 15), suggesting possible more duplication events of SPL genes in Petunia genome or faster loss of some members in other Solanaceae species. For instance, there are two orthologs in petunia corresponding to one gene in tomato for several members, such as PhSPL4a and PhSPL4b vs. SlySBP4, PhSPL6a and PhSPL6b vs. SlySBP6b, PhSPL12a and PhSPL12c vs. SlySBP12a, PhSPL12b and PhSPL12d vs. SlySBP12b, and PhSPL9a and PhSPL9b vs. SlySBP15 (Fig. 6). The PhSPL12b and PhSPL12d gene pair was evidently produced by a more recent additional duplication in Petunia, but for other members it also could be resulted from the loss of duplicated genes in tomato. In addition, tomato has no counterparts of PhSPL4c and PhSPL9c, suggesting they may also had lost. The duplicated genes are usually 


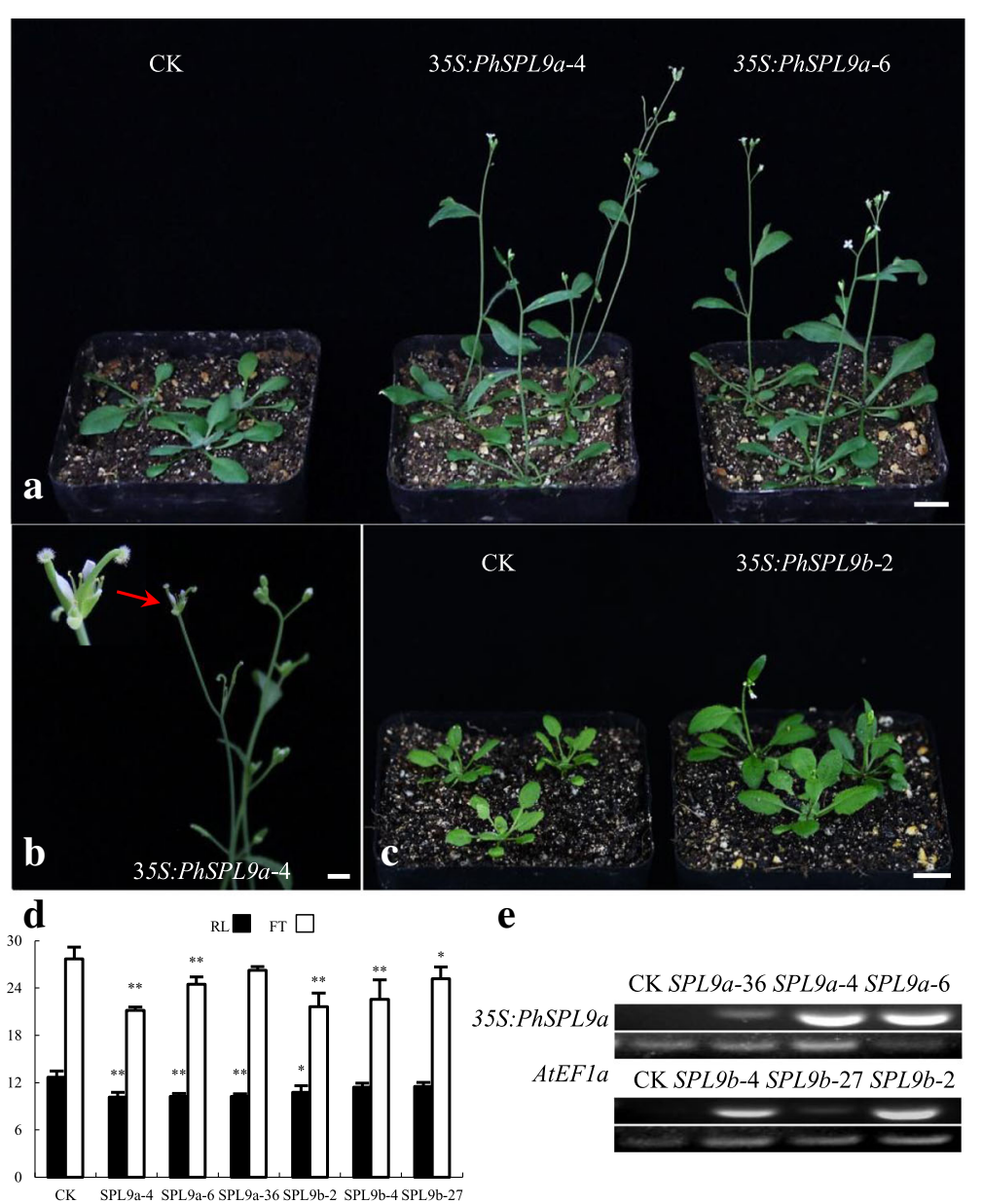

Fig. 8 Phenotypic analyses of transgenic Arabidopsis plants ectopically expressing PhSPL9a and PhSPL9b. gene. a The control (CK, left) and 35S:PhSPL9a transgenic plants (right) showing early flowering. b 35S:PhSPL9a transgenic plants showing determinate inflorescence with a terminal polygynoecial flower (close-up). c CK (left) and 35S:PhSPL9b transgenic plants (right) showing early flowering. $\mathbf{d}$ The numbers of rosette leaves (RL) and flowering time (FT) in CK, 35S:PhSPL9a and 35S:PhSPL9b transgenic lines; asterisks indicate statistically significant differences $\left({ }^{*} P<0.05\right.$, ** $\left.P<0.01\right)$ from the CK plants. e RT-PCR analysis of transgenes in CK and transgenic Arabidopsis lines. Bars: $10 \mathrm{~mm}(\mathbf{a}, \mathbf{c}), 1 \mathrm{~mm}$ (b)

followed by two kinds of destiny: loss of function by pseudogenization, or evolution of function via subfunctionalization or neofunctionalization. Petunia contains more $S P L$ genes than the other Solanaceae species suggests that the SPLs in Petunia may undergo fast functional evolution. Similarly, there are much more Group IV SPL members in Petunia than in Arabidopsis, five vs. one, suggesting these duplicated genes must undergo fast subfunctionalization or neofunctionalization, and may play redundant but divergent functions. Phylogenetic analysis indicated that 21 petunia $S P L$ genes can be divided into eight groups (Group I-VIII), which is consistent with the results of SPLs from Arabidopsis [8] and tomato [11]. The Group I is corresponding to the first lineage (group I) described by Zhang et al. [55], and contains only one member (PhSPL7); the Group II is corresponding to the subgroup II-1 in the second lineage described by Zhang et al. [55], and contains 4 members
(PhSPL12a-d). This phylogenetic relationship is in accordance with the result described by Zhang et al. [55], but different from that reported by Preston and Hileman [8], maybe due to different algorithms being used. Within each group, the exon-intron structures are almost constant, but it varied among different groups, such as the Group I and II genes are evidently longer and contain more exons compared to the other groups (10-11 vs. $2-4)$, which is consistent with the situation in most species, including monocots rice and maize [8], suggesting the $S P L$ gene structures are relatively conserved during the evolution.

All PhSPLs contained highly conserved SBP domain with 76 amino acid residues except for PhCNR that possess only the front part of the SBP domain (Fig. 1) and lack the motif 2 and 3 (Fig. 5) due to a nonsense mutation at the middle of SBP domain, i.e. PhCNR gene contains a premature stop codon and encodes a truncated protein with only 94 amino acids (Table 1). The same mutation was found in 
PaCNR of $P$. axillaris (Additional file 1) but not in PiCNR of $P$. inflata, however, a 55-bp deletion resulting in frame shift and premature translation termination was found in $P i C N R$ (Additional file 2), suggesting that the CNR in Petunia might be pseudogenization, which was supported further by the fact that no CNR ortholog was identified in $P$. exserta transcriptome (Additional file 3), but it was indeed expressed in P. axillaris, P. inflata, and W115. Similar motifs and their positions were revealed in the same group of PhSPLs and comparable with the results in other plant species, especially for the Group I and II genes, which supports the results reported by Zhang et al. [55] that group I and subgroup II-1 genes are constrained by stronger purifying selection and evolved at a lower substitution rate than II-2 genes. The erratic gene is SPL9c, which was phylogenetically closer to the genes of Group IV (Fig. 2), but has more similar gene length and intronexon structure to members in Group VIII (Additional files 1 and 2), so we designated it as the genes in Group VIII. However, unlike the other two members (SPL9a and SPL9b) of Group VIII, SPL9c lack the motif 18, which is similar to the members in Group IV (Fig. 5).

Multiple alignments of the coding sequences of PhSPL genes with the orthologs from $P$. axillaris, $P$. inflata, $P$. integrifolia, and P. exserta demonstrated that most PhSPL genes were derived from $P$. axillaris, which is in consistent with the fact that $P$. hybrida 'Mitchell' is a backcross hybrid of $P$. axillaris $\times(P$. axillaris $\times P$. hybrida 'Rose of Heaven'). Sequence alignment analysis in our study suggested that several PhSPL genes including PhSPL2, PhSPL4b, PhSPL9a/b/c and PhSPL13 may have a hybrid origin from $P$. axillaris and $P$. integrifolia/P. inflata or some other wild species such as $P$. exserta.

It has been reported that most SBP-box family of genes are targeted by miR156/157 in a number of plant species, such as 10 of 16 Arabidopsis SPL genes are the targets of miR156/157 [3, 23], 11 of 19 OsSPL genes are predicted to be targeted by OsmiR156 in rice [3, 23], and 10 of 15 SPL genes were found to be targets of miR156 in tomato [11]. A target search of PhmiR156/ 157 against the coding regions and 3' UTRs of petunia SPLs indicated that 14 out of 21 (two-thirds) PhSPL genes were potential targets of PhmiR156/157. All the putative PhmiR156-targeted PhSPL genes were clustered into groups IV to VIII, and miR156/157-targeting sites in $10 \mathrm{PhSPLs}$ belonging to groups IV, V, VII and VIII locate in the coding region, while the target sites for other 4 PhSPLs belonging to group VI locate in the 3' UTRs (Fig. 6), which is consistent with the results from other plants [58], suggesting miR156/157-mediated posttranscriptional regulation of SPLS is a highly conserved mechanism in plants. In animals, miRNAs are prone to act by repressing translation and their target sites are mostly found in 3' UTRs, however, plant miRNAs were believed to exert their function mainly by mediating target cleavage, so the target sites are often located in ORFs that may facilitate the destruction of target mRNA after cleavage. Besides cleavage, accumulating genetic evidence indicates that plant miRNAs also can mediate translation repression, in which situation the target sites could be located in 3' UTRs or ORFs [59]. Petunia group IV, V, VII and VIII SPL genes contain their miR156/157-binding sites in the coding region suggests they may be regulated by miRNA-mediated cleavage, while the group VI genes with the target sites in 3' UTRs should be controlled by translation repression.

Expression patterns and potential functions of PhSPL genes At present, there was few functional data of SPL genes available in petunia. Usually, the gene functions are expected to correlate in a large extent with their expression patterns. In this study, the expression of PhSPL genes in various tissues were investigated by qPCR analysis, which indicated PhSPLs exhibited distinct expression patterns in terms of specificity and expression level (Fig. 7). Similar to the results from many other species, where $S P L$ genes exhibited higher expression levels in the shoot apices (apical buds), inflorescences (panicles), and flower buds [11, 13, 60], most PhSPLs expressed predominantly in the axillary buds, inflorescences, and/or flower buds (Fig. 7), suggesting they might be involved in the development of these organs in petunia. There is no obvious correlation between gene structures and expression patterns, although some genes within the same group demonstrated similar expression profiles.

SPL Group I and II genes are characterized by their large size and lack of miR156 and miR157-binding sites. Previous studies demonstrated that these two groups of $S P L$ genes were almost ubiquitously expressed across different plant organs $[8,55]$. For instance, SlySBP7, the Group I gene in tomato, is expressed in seedlings, roots, stems, leaves, vegetative shoot apices, inflorescences, flowers, and fruits [11]; the four Arabidopsis Group II genes, AtSPL1, AtSPL12, AtSPL14, and AtSPL16, are expressed wildly in seedlings, roots, rosette and cauline leaves, shoot apical meristem, flowers, and fruits [3, 8]. Petunia Group I (PhSPL7) and Group II (PhSPL12a/b/c/d) genes also showed ubiquitous expression in all tested tissues, although they were expressed most strongly in different tissues, and PhSPL12c exhibited much lower expression levels than other genes (Fig. 7). Currently, the only functional analysis of Group I genes is limited to Arabidopsis SPL7 (AtSPL7), which was characterized to play a pivotal role in the regulation of copper homeostasis [32]. PhSPL7 may have similar functions to AtSPL7 based on their conserved gene structures and expression patterns. Functional data for Group II genes exist for two members, PpSBP2 and AtSPL14. Like AtSPL7, PpSBP2 is involved in the regulation of copper 
homeostasis in Phycomitrella patens [61], while AtSPL14 is involved in response to the fungal toxin fumonisin B1 (FB1) and may also function to delay the juvenile to adult transition [38]. Functional diversification in Group II make the function prediction of $P h S P L 12 a / b / c / d$ genes unreliable, while their expression patterns suggest that they should play redundant roles in regulating the development of axillary buds, inflorescences and/or flowers, with PhSPL12c may also in cotyledon development. It might also be of interest to investigate if PhSPL12a to PhSPL12d are associated with programmed cell death in response to the FB1 in petunia.

Group III SPL genes also lack the miR156/157-binding site, although short relative to Group I and II genes. The first Group III gene to be functionally characterized was AtSPL8 in Arabidopsis, which is a tissue-dependent regulator of GA response and regulate early anther development and gynoecium differential patterning, trichome formation on sepals, stamen filament elongation, and root growth [34-37]. High expression of the AtSPL8 orthologs SlySBP8a and SlySBP8b in inflorescences, carpels, and young fruits but very low in roots, seedlings, and stamens of tomato suggests at least partial conservation of function in gynoecium differentiation [11]. In maize and rice, AtSPL8 ortholog (LG1 and OsLG1, respectively) is involved in development of the ligule and auricule [42, 43], and controls the branch angle of tassel and panicle, respectively [44-46]. PhSPL8 was expressed more highly in inflorescences, flower buds, and young fruits versus other tissues, suggesting it may play partial conserved roles in inflorescence, anther and gynoecium development.

Group IV contains only one SPL gene (AtSPL6) in Arabidopsis, but three genes $(S l y S B P 6 a / b / c)$ in tomato, five genes (PhSPL6a/b/c/d/e) in petunia (Fig. 2), five genes (PpSBP3/6/6b/13/14) in Phycomitrella, and no orthologs in the fully sequenced genomes of rice and other grasses [8], suggesting a loss of this gene lineage at least in some monocots and differential duplication and expansion in different species. AtSPL6 and its ortholog NbSPL6 of Nicotiana benthamiana play a conserved role in the TIRNB-LRR receptor-mediated plant innate immunity [31], while the function of $P p S B P 3$ was characterized to repress reproduction development [62]. In petunia, expression of the five Group IV SPL genes suggests divergence of function. Similar to AtSPL6 and SlySBP6a [10, 11], PhSPL6a and $P h S P L 6 b$ were expressed constitutively across the plant, but PhSPL6a expressed predominantly in axillary buds, flower buds, and roots while PhSPL6b expressed mainly in roots, inflorescences, and axillary buds. By contrast, PhSPL6c and PhSPL6d expression was somewhat tissuespecific and confined primarily to the axillary buds and inflorescences; PhSPL6e showed very low expression and mainly in axillary buds, bracts and cotyledons (Fig. 7). The additional duplications of SPL6 in petunia also suggest functional redundancy, which need to be characterized yet.

Group V contains three SPL genes (AtSPL2, AtSPL10, and AtSPL11) in Arabidopsis, while only one member (PhSPL2) exists in petunia. Recent studies demonstrated that AtSPL2/10/11 have overlapping functions in promoting vegetative phase change and flowering [9]. AtSPL2 might also control floral organ development and plant fertility by directly regulating ASYMMETRIC LEAVES 2 (AS2) expression [28]. It is interesting that PhSPL2 was expressed mainly in bracts and inflorescences, which is different from the constitutive expression of AtSPL2/10/ 11 and tomato orthologs SlySBP2 and SlySBP10 [11, 63]. The special expression pattern of PhSPL2 suggests a distinct function from Arabidopsis genes, which remains to be revealed.

AtSPL3/4/5 are Group VI SPL genes in Arabidopsis, which were previously considered to redundantly promote vegetative phase change and flowering based on the overexpression data [29]. Recent detailed analysis of $s p l$ mutants, however, revealed that AtSPL3/4/5 play a major role in floral meristem identity transition rather than in vegetative morphogenesis or flowering induction [9]. Similar to Arabidopsis, the single AtSPL3/4/5 ortholog AmSBP1 in snapdragon (Antirrhinum majus) is involved in initiating flower development after the switch to inflorescence development; silencing of $A m S B P 1$ also causes an increase in vegetative branching under long days [64]. By contrast, the tomato AtSPL3 ortholog CNR is required for fruit ripening [47]. In petunia, there are five Group VI SPL genes, PhSPL3, PhSPL4a, PhSPL4b, PhSPL4c, and $P h C N R$, with significantly different expression patterns and levels (Fig. 7). A recent study demonstrated that PhSBP1 (PhSPL3) and PhSBP2 (PhSPL4c) differentially promote discrete stages of the reproductive transition, and $P h S B P 1$, possibly also $P h C N R$, accelerates leaf initiation rate [49]. This is consistent with the relatively high expression of PhSPL3 and PhSPL4c in axillary buds, inflorescences, and late stage of shoot apices (Fig. 7) [49]. PhCNR also expressed mainly in axillary buds, however, our sequence analysis demonstrated that $P h C N R$, as well as $P a C N R$ and $P i C N R$, is likely to be pseudogene due to nucleotide change or deletion mutation. Compared with PhSPL3 and PhSPL4c, PhSPL4a and PhSPL4b showed much lower expression, especially PhSPL4a that only expressed very faintly in inflorescence and cotyledon (Fig. 7). The differential expression was also found in tomato Group VI SPL genes, SlySBP3, SlySBP4, and CNR [11], suggesting divergent and elusive evolution of functions in this group.

Expression and functional data demonstrated that Group VII SPL genes were involved in various aspects of above ground plant development. In Arabidopsis, the single SPL Group VII gene AtSPL13 has been implicated in the regulation of the post-germinative switch from the cotyledon 
stage to the vegetative-leaf stage [65]; it also plays overlapping roles with SPL2/10/11 and SPL9/15 in promoting vegetative and reproductive phase change [9]. In contrast, the AtSPL13 ortholog in maize and rice, TGA1 and OsSPL16, is involved in ear glume development [39] and controls grain size, shape and quality, respectively [40, 41], suggesting divergent functional evolution of the Group VII SPL genes. Different from AtSPL13 that is expressed highly in the hypocotyl, shoot apical meristem, leaf primordia, and developing inflorescence [9, 65], PhSPL13 expressed mainly in inflorescence and bract in petunia (Fig. 7), suggesting it might have distinct functions from AtSPL13.

Similar to AtSPL2/10/11, AtSPL9 and AtSPL15 belonging to Group VIII also contribute to both the vegetative and reproductive phase change, and play more important role than SPL2/10/11 [9]. AtSPL9 was also suggested to be involved in petal trichome initiation, anthocyanin pigment accumulation, and sesquiterpene biosynthesis [66-68]. The genome-wide analysis indicated that petunia contains three Group VIII SPL genes, PhSPL9a, PhSPL9b, and PhSPL9c. The expression of PhSPL9a and PhSPL9c was mainly in the inflorescences, while PhSPL9b was expressed constitutively in all tissues, although with relatively low expression levels (Fig. 7). Overexpression of PhSPL9a or PhSPL9b in Arabidopsis resulted in early flowering with significantly reduced number of rosette leaves, suggesting PhSPL9a and PhSPL9 $b$ may have conserved functions in promoting the vegetativeto-reproductive phase transition. However, differential expression pattern between PhSPL9a and PhSPL9b implied their distinct functions in petunia, which awaits to be characterized in the future.

\section{Conclusion}

We identified 21 putative $S P L$ genes within $P$. axillaris and $P$. inflata genome, respectively, which was confirmed by cloning from $P$. hybrida W115. The analyses of gene structure, expression pattern, and potential functions of petunia SPLS support that the plant SBP-box genes are conserved gene family, but underwent differential expression and functional evolution within different groups and species. The present work provides an important foundation for the future elucidation of the biological functions of petunia $S P L$ genes.

\section{Methods}

\section{Plant materials and bacterial strains}

The plant materials used in this study included Petunia hybrida line W115 (Mitchel diploid) and Col-0 ecotype of Arabidopsis thaliana. They were grown under longday conditions ( $16 \mathrm{~h} \mathrm{light/8} \mathrm{h}$ dark) with $75 \%$ humidity in a growth chamber at $21-22{ }^{\circ} \mathrm{C}$.
Escherichia coli strain DH5 $\alpha$ was used as host in cloning of the coding sequences of PhSPL genes. Agrobacterium tumefaciens strain GV3101 was used for transformation of Arabidopsis.

\section{Identification and cloning of SPL genes in Petunia}

Petunia SBP-box genes were identified from $P$. axillaris $\mathrm{N}$ and $P$. inflata S6 genome databases in Sol Genomics Network (https://solgenomics.net/) [50] by BLAST homology search using the nucleotide and protein sequences of 16 Arabidopsis SPL genes [10], 15 tomato SBP-box genes [11], and 22 Nicotiana tomentosiformis SPL genes (Additional file 9), respectively. The transcriptome databases of Petunia species including $P$. axillaris, $P$. integrifolia, $P$. exserta and $P$. inflata in the NCBI $[52,69]$, and P. hybrida 'Mitchell' in Sol Genomics Network [70] were searched for the transcripts of Petunia SBP-box genes by nucleotide BLAST with identified Petunia SPL genes.

To confirm the results, gene-specific primers (Additional file 6) were designed to amplify the complete coding sequences of PhSPL genes from P. hybrida line W115. Total RNA was extracted from mix samples of seedlings, leaves, inflorescences and flowers with RNA pure Total RNA Kit (Aidlab, China). $2 \mu \mathrm{g}$ of RNA was used for cDNA synthesis (Takara, Japan), the resulting cDNA was diluted 1:10, and then $2 \mu \mathrm{l}$ was used in PCR with $2 \times$ High-Fidelity Master Mix DNA Polymerase (Tsingke, China). The PCR conditions were $94{ }^{\circ} \mathrm{C}$ for $4 \mathrm{~min}$, followed by $32-35$ cycles of $94{ }^{\circ} \mathrm{C}$ for $30 \mathrm{~s}, 55-60{ }^{\circ} \mathrm{C}$ for $30 \mathrm{~s}, 72{ }^{\circ} \mathrm{C}$ for $1-3 \mathrm{~min}$, and a final extension of $72{ }^{\circ} \mathrm{C}$ for $10 \mathrm{~min}$. PCR products were purified from agarose gel with Axyprep DNA Gel Extraction Kit (Axygen, USA), then cloned into pMD18-T (Takara, Japan) and transformed into E. coli DH5 $\alpha$, and 4-5 positive clones for each gene were selected randomly for sequencing analysis (Augct, China).

\section{Multiple sequence alignments and phylogenetic analysis} The coding sequences of the orthologous SPL genes in $P$. axillaris, $P$. inflata and $P$. exserta were deduced from the genomic DNA sequences and/or the cDNA sequences from transcriptome databases by BLAST search and alignment with the confirmed coding sequences of PhSPL genes. These nucleotide sequences were first aligned with the MUSCLE program implemented in MEGA 6.0 [71]. Phylogenetic tree of the nucleotide sequences of PhSPL genes and their orthologous genes in $P$. axillaris, $P$. inflata and $P$. exserta was constructed using MEGA 6.0 with the Neighbor-Joining (NJ) method and 1000 bootstrap replicates.

The SPL protein sequences of Arabidopsis and tomato were downloaded from the website of TAIR (http:// www.arabidopsis.org/) and the tomato genome database in Sol Genomics Network, respectively. Multiple alignments of the conserved SBP domains (76 aa) of protein 
sequences encoded by SPL genes of petunia, Arabidopsis and tomato were conducted by the ClustalW program of MEGA 6.0. Phylogenetic relationship of SBP-box genes was estimated using the maximum likelihood (ML) method in MEGA 6.0, and bootstrap values were calculated with 500 replicates.

\section{Analyses of the gene structure and conserved motifs in PhSPL genes}

The Gene Structure Display Server 2.0 (http://gsds.cbi.p ku.edu.cn/) was used to predict the exon-intron structure and locations of PhSPL genes in the downloaded genomic sequences [72]. Conserved domains of PhSPL proteins were identified using the Conserved Domain Database (CDD) in NCBI with default parameters [73]. The MEME (Multiple Expectation Maximization for Motif Elicitation) 4.12.0 (http://meme-suite.org/tools/meme) was used to predict both conserved and potential motifs of the putative PhSPL protein sequences using the parameter settings: the minimum motif width $=6$, the maximum motif width $=$ 50 , and the maximum number of motifs $=20$ [74].

\section{Prediction of miR156/157-targeted PhSPLs}

PhSPLs potentially targeted by miR156/157 were determined with petunia miR156/157 sequences [50] against the coding regions and 3'-UTRs of all PhSPLs for complementary sequences of PhmiR156/157 on the psRNATarget server (http://plantgrn.noble.org/psRNATarget/) with default parameters [75].

\section{Expression pattern analyses of PhSPL genes by real-time quantitative RT-PCR}

Different vegetative and reproductive tissues were harvested from petunia line W115, represented by germinating seeds (3d after sowing), cotyledons (7d after sowing), young seedlings (four euphylla stage), roots, stems, leaves and axillary buds of adult plants (after flowering), bracts, inflorescences, flower buds $(0.5 \mathrm{~cm})$, and young fruits ( $7 \mathrm{~d}$ after pollination). All samples were frozen in liquid nitrogen immediately after collection and stored at $-80{ }^{\circ} \mathrm{C}$ until used for qPCR analysis.

Total RNA was extracted with RNA pure Total RNA Kit (Aidlab, China). First-strand cDNA synthesis was carried out with $2 \mu \mathrm{g}$ of total RNA for each sample using the PrimeScript $^{\mathrm{ma}}$ RT reagent Kit with gDNA Eraser (Takara, Japan). Real-time quantitative RT-PCR (qPCR) was performed with the SYBR Premix Ex Taq (Takara, Japan) and the ABI7500 Real-Time System (Applied Biosystems, USA) to reveal the expression level of PhSPL genes in various tissues. qPCR products were amplified with $1 \mu \mathrm{l}$ template of 20 -fold diluted RT reaction mixture, $5 \mu \mathrm{l} 2 \times$ SYBR Green Master Mix, $0.2 \mu \mathrm{l}$ forward and reverse primers $(10 \mu \mathrm{mol} / \mu \mathrm{l})$, and water to a final volume of $10 \mu \mathrm{l}$. The transcript levels of PhEF1 $\alpha$ was determined for reference
[76]. qPCR was performed with three biological replicates for each sample and the mean values \pm SD (standard deviation) were calculated. Data was analyzed using the $2^{-\Delta \Delta C T}$ method [77]. All the primers were designed by PrimerBLAST online (http://www.ncbi.nlm.nih.gov/tools/pri mer-blast/) to avoid conserved regions and listed in Additional file 6. Product size was $120-300$ bp. Primer specificity was tested via PCR using recombinant plasmid DNA containing purpose fragment.

\section{Vector construction and plant transformation}

The full-length cDNA sequences of the PhSPL9a and PhSPL9b genes were amplified and cloned into pMD-18 T vector (Takara, Japan). Sequence accuracy and insertion direction were confirmed by sequencing. Digestion of these vectors was conducted using SalI and BamHI (Takara, Japan) restriction endonuclease enzymes, and the digested products were ligated into the appropriate sites of pCAMBIA2300 vector containing the CaMV35S promoter, to create the constructs 35S:PhSPL9a and 35S:PhSPL9b. All the constructed plasmids were confirmed by PCR and restriction digestions. Agrobacterium tumefaciens GV3101 containing the respective expression vectors was used for Arabidopsis (Col-0) transformation via the floral dip method. The transformed seeds were surface-sterilized with $8 \%(v / v)$ sodium hypochlorite solution for $4 \mathrm{~min}$ followed by $95 \%(\mathrm{v} / \mathrm{v})$ ethanol for $2 \mathrm{~min}$, then rinsed 3 times in sterile water and screened on half-strength Murashige and Skoog (1/2MS) medium supplemented with $50 \mathrm{mg} / \mathrm{L}$ kanamycin sulfate (Biosharp, China) and $50 \mathrm{mg} / \mathrm{L}$ cefotaxime sodium salt (Biosharp, China). The plants that survived were transplanted into soil and grown under long-day conditions ( $16 \mathrm{~h}$ light/8 h dark) at $22{ }^{\circ} \mathrm{C}$ to obtain self-pollinated seeds.

\section{Phenotype and transgene expression analysis}

Following the segregation tests, 32 kanamycin-resistant transgenic plants of the $T_{2}$ generation lines which fitted a segregation ratio of 3:1 were chosen to record flowering time and floral phenotype. Seedlings were grown in a growth incubator at $22{ }^{\circ} \mathrm{C}$ under a long day (LD) conditions (16/8 h, light/dark). Flowering time and the number of rosette leaves were measured when the plants bore a $1 \mathrm{~cm}$ long inflorescence.

RT-PCR was performed to analysis the expression of the transgene in Arabidopsis, which were carried out on 14-d-old seedlings. Total RNA was isolated and then reverse-transcribed from the control plants (Col-0 Arabidopsis transformed with the empty pCAMBIA2300 plasmid) and $\mathrm{T}_{1}$ transgenic lines with the same reagent kit described above. Arabidopsis EF1 $\alpha$ gene was used as the reference gene to normalize small differences in template amounts. Primers used for the detection of PhSPL9a 
and PhSPL9b expression levels in the transgenic plants were listed in Additional file 6.

\section{Statistical analysis}

Statistical differences were analyzed using ANOVA (analysis of variance) in IBM SPSS Statistics 22 based on Duncan's multiple range test $(P<0.05)$.

\section{Additional files}

Additional file 1: Orthologous SPL genes in P. axillaris N genome. ${ }^{a}$ Sequence ID corresponds to annotations provided by https:/solgenomics.net/organism/ Petunia_axillaris/genome (v1.6.2) [50]. ${ }^{\mathrm{b}}$ The transcripts were identified by nucleotide BLAST search of the TSA (Transcriptome Shotgun Assembly) database of Petunia axillaris in the NCBI and confirmed by alignment with AlignX program in Vector NTI Advance v11.5.2 [57]. (DOCX 18 kb)

Additional file 2: Orthologous SPL genes in $P$. inflata $\$ 6$ genome and $P$. intergifolia transcriptome. ${ }^{a}$ Sequence ID corresponds to annotations provided by https://solgenomics.net/organism/Petunia_axillaris/genome (v1.0.1) [50] ${ }^{\mathrm{b}}$ The transcripts were identified by nucleotide BLAST search of the TSA (Transcriptome Shotgun Assembly) database of Petunia integrifolia (GBRV) and P. integrifolia Subsp. inflata (GBDS) in the NCBI and confirmed by alignment with AlignX program in Vector NTI Advance v11.5.2 [57]. '/' indicates no orthologous transcript was found. (DOCX $22 \mathrm{~kb}$ )

Additional file 3: Orthologous SPL genes in the transcriptome database of P. exserta [51]. The genes were identified by nucleotide BLAST search of the TSA (Transcriptome Shotgun Assembly) database of Petunia exserta in the NCBI with PhSPL genes and confirmed by alignments with AlignX program in Vector NTI Advance v11.5.2. '-' indicated no transcripts was identified. Partial. represent the ORF sequence was not complete [57]. (DOCX $14 \mathrm{~kb}$ )

Additional file 4: The analysis of nucleotide differences and the resultant amino acid variations between PhSPL genes and their orthologs in $P$. axillaris $N$, $P$. inflata $56, P$. intergifolia and $P$. exserta. 'I' indicates no ortholog was identified in this species; '-' indicates no protein can be translated for this gene. (DOCX $16 \mathrm{~kb}$ )

Additional file 5: The specific information of conserved and potential motifs in PhSPL protein sequences predicted by MEME. (DOCX $1340 \mathrm{~kb}$ )

Additional file 6: Primers used in this study. a Primer pairs used for the cloning of complete CDS. b Primer pairs used for qRT-PCR and transgene RT-PCR. (DOCX $18 \mathrm{~kb})$

Additional file 7: Heat map of PhSPL genes expression in various tissues. Differences in gene expression are shown in color according to the scale. $R$, roots; $S$, stems; $L$, leaves; $A b$, axillary buds; If, inflorescencess; $\mathrm{Fb}$, flower buds; Fr, young fruits; Sl, young seedlings; Gs, germinating seeds; Br, bracts; Co, cotyledons. (DOCX 89 kb)

Additional file 8: Phenotypes of the transgenic Arabidopsis plants overexpressing PhSPL9a and PhSPL9b genes. $32 \mathrm{~T}_{2}$ transgenic plants of putative single-copy transgenic lines were chosen to record flowering time and floral phenotype. Values are mean $\pm \mathrm{SD}(n=32)$. Asterisk indicated significant difference in comparison with the empty plasmid transgenic Col-0 plants (CK) ${ }^{*} P<0.05$ and $\left.{ }^{* *} P<0.001\right)$. (DOCX $12 \mathrm{~kb}$ )

Additional file 9: SPL genes of Nicotiana tomentosiformis annotated in $\mathrm{NCBI}$ [19]. (DOCX $15 \mathrm{~kb})$

\section{Abbreviations}

ML: maximum likelihood; NJ: Neighbor-Joining; NLS: nuclear localization signal; qPCR: real-time quantitative RT-PCR; RT-PCR: reverse transcription PCR; SBP: SQUAMOSA PROMOTER BINDING PROTEIN; SPL: SQUAMOSA PROMOTER BINDING PROTEIN-LIKE; TFs: transcription factors; UTR: untranslated region

\section{Acknowledgements}

We thank all colleagues in our laboratory for helpful discussions and technical assistance.

\section{Funding}

This work was financially supported by the National Natural Science Foundation of China (No. 31471914, 31772345) and the Ministry of Education of China (IRT13065). The funding bodies had no role in the design of the study and collection, analysis, and interpretation of data and in writing the manuscript.

\section{Availability of data and materials}

The genome sequences of $P$. axillaris and $P$. inflata used for identifying the SBP-box genes in current study were located in Sol Genomics Network (https://solgenomics.net/organism/Petunia_axillaris/genome and https:// solgenomics.net/organism/Petunia_inflata/genome, respectively) [50]. The transcriptome databases used to identify SPL genes of P. axillaris, P. exserta and $P$. integrifolia were available in NCBI under accessions GBRU01000000, GBRT01000000, and GBRV01000000, respectively.[51] The transcriptome databases of $P$. inflata were available in NCBI under accessions GBDS00000000, GBDR00000000, and GBDQ00000000.[67] The transcriptome sequences of $P$. hybrida 'Mitchell' was located in Sol Genomics Network (https://solgenomics.net/) [68]. The sequences information of PhSPLs were registered in the NCBI (accession number MF580469-MF580489).

\section{Authors' contributions}

QZ designed and performed the experiments, carried out the bioinformatics analyses, and drafted the manuscript. SSZ participated in guiding and carrying out some experiments. FC participated in gene expression analysis. BJL, LW, and FL participated in data analysis and taking care of the plant materials. JQZ participated in directing the study. MZB participated in the design of this project. GFL, as the corresponding author, provided the idea and designed the framework of this study, and modified the manuscript. All authors read and approved the final manuscript.

\section{Ethics approval and consent to participate}

The seeds of Petunia hybrida line W115 (Mitchel diploid) and Col-0 ecotype of Arabidopsis thaliana were collected in Huazhong Agricultural University (HZAU), China. These plant materials are widely used laboratory strains all over the world. No permits are required for the collection of plant samples. The plant materials are maintained following the institutional guidelines of College of Horticulture and Forestry Sciences, HZAU, China. All the experiments including field studies were conducted in accordance with China's legislation and the regulations of HZAU. This article did not contain any studies with human participants or animals, and did not involve any endangered or protected species.

\section{Consent for publication}

Not applicable.

\section{Competing interests}

The authors declare that they have no competing interests.

\section{Publisher's Note}

Springer Nature remains neutral with regard to jurisdictional claims in published maps and institutional affiliations.

\section{Author details}

'Key Laboratory of Horticultural Plant Biology, Ministry of Education; Key Laboratory of Urban Agriculture in Central China, Ministry of Agriculture; College of Horticulture and Forestry Sciences, Huazhong Agricultural University, Shizishan Street No. 1, Wuhan 430070, China. ${ }^{2}$ Wuhan Institute of Landscape Architecture, Peace Avenue No. 1240, Wuhan 430081, China.

Received: 2 November 2017 Accepted: 8 February 2018 Published online: 12 March 2018

\section{References}

1. Jin J, Tian F, Yang DC, Meng YQ, Kong L, Luo J, Gao G. PlantTFDB 4.0: toward a central hub for transcription factors and regulatory interactions in plants. Nucleic Acids Res. 2017;45(Database issue):D1040-5

2. Klein J, Saedler H, Huijser P. A new family of DNA binding proteins includes putative transcriptional regulators of the Antirrhinum majus floral meristem identity gene SQUAMOSA. Mol Gen Genet. 1996;250(1):7-16.

3. Yang Z, Wang X, Gu S, Hu Z, Xu H, Xu C. Comparative study of SBP-box gene family in Arabidopsis and rice. Gene. 2008;407(1-2):1-11. 
4. Birkenbihl RP, Jach G, Saedler H, Huijser P. Functional dissection of the plant-specific SBP-domain: overlap of the DNA-binding and nuclear localization domains. J Mol Biol. 2005;352(3):585-96.

5. Yamasaki K, Kigawa T, Inoue M, Tateno M, Yamasaki T, Yabuki T, Aoki M, Seki E, Matsuda T, Nunokawa E, et al. A novel zinc-binding motif revealed by solution structures of DNA-binding domains of Arabidopsis SBP-family transcription factors. J Mol Biol. 2004;337(1):49-63.

6. Kropat J, Tottey S, Birkenbihl RP, Depege N, Huijser P, Merchant S. A regulator of nutritional copper signaling in Chlamydomonas is an SBP domain protein that recognizes the GTAC core of copper response element. Proc Natl Acad Sci U S A. 2005;102(51):18730-5.

7. Liang $X$, Nazarenus TJ, Stone JM. Identification of a consensus DNA-binding site for the Arabidopsis thaliana SBP domain transcription factor, AtSPL14, and binding kinetics by surface plasmon resonance. Biochemistry. 2008;47(12): 3645-53.

8. Preston JC, Hileman LC. Functional evolution in the plant SQUAMOSAPROMOTER BINDING PROTEIN-LIKE (SPL) gene family. Front Plant Sci. 2013;4:80.

9. Xu M, Hu T, Zhao J, Park MY, Earley KW, Wu G, Yang L, Poethig RS. Developmental functions of miR156-regulated SQUAMOSA PROMOTER BINDING PROTEIN-LIKE (SPL) genes in Arabidopsis thaliana. PLoS Genet. 2016;2(8):e1006263.

10. Cardon GHS, Klein J, Nettesheim K, Saedler H, Huijser P. Molecular characterisation of the Arabidopsis SBP-box genes. Gene. 1999;237:91-104.

11. Salinas M, Xing S, Hohmann S, Berndtgen R, Huijser P. Genomic organization, phylogenetic comparison and differential expression of the SBP-box family of transcription factors in tomato. Planta. 2012;235(6):1171-84.

12. Hou H, Li J, Gao M, Singer SD, Wang H, Mao L, Fei Z, Wang X. Genomic organization, phylogenetic comparison and differential expression of the SBP-box family genes in grape. PLoS One. 2013;8(3):e59358

13. Li J, Hou H, Li X, Xiang J, Yin X, Gao H, Zheng Y, Bassett CL, Wang X. Genome-wide identification and analysis of the SBP-box family genes in apple (Malus $\times$ domestica Borkh.). Plant Physiol Bioch. 2013;70:100-14.

14. Zhang SD, Ling LZ. Genome-wide identification and evolutionary analysis of the SBP-box gene family in castor bean. PLoS One. 2014;9(1):e86688.

15. Li C, Lu S. Molecular characterization of the SPL gene family in Populus trichocarpa. BMC Plant Biol. 2014;14:131.

16. Shalom L, Shlizerman L, Zur N, Doron-Faigenboim A, Blumwald E, Sadka A. Molecular characterization of SQUAMOSA PROMOTER BINDING PROTEIN-LIKE (SPL) gene family from citrus and the effect of fruit load on their expression. Front Plant Sci. 2015;6:389.

17. Zhang $X$, Dou L, Pang C, Song M, Wei H, Fan S, Wang C, Yu S. Genomic organization, differential expression, and functional analysis of the $S P L$ gene family in Gossypium hirsutum. Mol Genet and Genomics. 2015;290(1):115-26.

18. Zhang HX, Jin JH, He YM, Lu BY, Li DW, Chai WG, Khan A, Gong ZH. Genome-wide identification and analysis of the SBP-box family genes under phytophthora capsici stress in pepper (Capsicum annuum L.). Front Plant Sci. 2016;7:504.

19. Han YY, Ma YQ, Li DZ, Yao JW, Xu ZQ. Characterization and phylogenetic analysis of fifteen NtabSPL genes in Nicotiana tabacum L. cv. Qinyan95. Dev Genes Evol. 2016;226(1):1-14.

20. Cheng H, Hao M, Wang W, Mei D, Tong C, Wang H, Liu J. Fu L, Hu Q. Genomic identification, characterization and differential expression analysis of SBP-box gene family in Brassica napus. BMC Plant Biol. 2016;16(1):196.

21. Tripathi RK, Goel R, Kumari S, Dahuja A. Genomic organization, phylogenetic comparison, and expression profiles of the SPL family genes and their regulation in soybean. Dev Genes Evol. 2017;227(2):101-19.

22. Pan F, Wang Y, Liu H, Wu M, Chu W, Chen D, Xiang Y. Genome-wide identification and expression analysis of SBP-like transcription factor genes in Moso bamboo (Phyllostachys edulis). BMC Genomics. 2017;18(1):486.

23. Wang $\mathrm{H}$, Wang $\mathrm{H}$. The miR156/SPL module, a regulatory hub and versatile toolbox, gears up crops for enhanced agronomic traits. Mol Plant. 2015;8(5): 677-88.

24. Chuck G, Cigan AM, Saeteurn K, Hake S. The heterochronic maize mutant Corngrass 1 results from overexpression of a tandem microRNA. Nat Genet. 2007;39(4):544-9.

25. Wu G, Poethig RS. Temporal regulation of shoot development in Arabidopsis thaliana by miR156 and its target SPL3. Development. 2006;133(18):3539-47.

26. Ferreira e Silva GF, Silva EM, Azevedo-Mda S, Guivin MA, Ramiro DA Figueiredo CR, Carrer H, Peres LE, Nogueira FT. microRNA156-targeted SPL/ SBP-box transcription factors regulate tomato ovary and fruit development. Plant J. 2014;78(4):604-18.
27. Yu N, Niu QW, Ng KH, Chua NH. The role of miR156/SPLs modules in Arabidopsis lateral root development. Plant J. 2015;83(4):673-85.

28. Wang Z, Wang Y, Kohalmi SE, Amyot L, Hannoufa A. SQUAMOSA PROMOTER BINDING PROTEIN-LIKE 2 controls floral organ development and plant fertility by activating ASYMMETRIC LEAVES 2 in Arabidopsis thaliana. Plant Mol Biol. 2016;92(6):661-74.

29. Yamaguchi A, Wu MF, Yang L, Wu G, Poethig RS, Wagner D. The microRNAregulated SBP-box transcription factor SPL3 is a direct upstream activator of LEAFY, FRUITFULL, and APETALA1. Dev Cell. 2009;17(2):268-78.

30. Jung JH, Lee HJ, Ryu JY, Park CM. SPL3/4/5 integrate developmental aging and photoperiodic signals into the FT-FD module in Arabidopsis flowering Mol Plant. 2016;9(12):1647-59.

31. Padmanabhan MS, Ma S, Burch-Smith TM, Czymmek K, Huijser P, DineshKumar SP. Novel positive regulatory role for the SPL6 transcription factor in the N TIR-NB-LRR receptor-mediated plant innate immunity. PLoS Pathog. 2013;9(3):e1003235.

32. Yamasaki H, Hayashi M, Fukazawa M, Kobayashi Y, Shikanai T. SQUAMOSA promoter binding protein-like 7 is a central regulator for copper homeostasis in Arabidopsis. Plant Cell. 2009;21(1):347-61.

33. Gielen H, Remans T, Vangronsveld J, Cuypers A. Toxicity responses of $\mathrm{Cu}$ and cd: the involvement of miRNAs and the transcription factor SPL7. BMC Plant Biol. 2016;16(1):145

34. Unte US, Sorensen AM, Pesaresi P, Gandikota M, Leister D, Saedler H, Huijser P. SPL8, an SBP-box gene that affects pollen sac development in Arabidopsis. Plant Cell. 2003;15(4):1009-19.

35. Xing S, Salinas M, Hohmann S, Berndtgen R, Huijser P. miR156-targeted and nontargeted SBP-box transcription factors act in concert to secure male fertility in Arabidopsis. Plant Cell. 2010;22(12):3935-50.

36. Zhang Y, Schwarz S, Saedler H, Huijser P. SPL8, a local regulator in a subset of gibberellin-mediated developmental processes in Arabidopsis. Plant Mol Biol. 2007;63(3):429-39.

37. Xing S, Salinas M, Garcia-Molina A, Hohmann S, Berndtgen R, Huijser P. SPL8 and miR156-targeted SPL genes redundantly regulate Arabidopsis gynoecium differential patterning. Plant J. 2013;75(4):566-77.

38. Stone JM, Liang X, Nekl ER, Stiers JJ. Arabidopsis AtSPL14, a plant-specific SBP-domain transcription factor, participates in plant development and sensitivity to fumonisin B1. Plant J. 2005;41(5):744-54.

39. Wang $H$, Nussbaum-Wagler $T, L i B$, Zhao Q, Vigouroux Y, Faller M, Bomblies K, Lukens L, Doebley JF. The origin of the naked grains of maize. Nature. 2005;436(7051):714-9.

40. Wang S, Wu K, Yuan Q, Liu X, Liu Z, Lin X, Zeng R, Zhu H, Dong G, Qian Q, et al. Control of grain size, shape and quality by OSSPL16 in rice. Nat Genet. 2012:44(8):950-4.

41. Wang S, Li S, Liu Q, Wu K, Zhang J, Wang S, Wang Y, Chen X, Zhang Y, Gao $C$, et al. The OsSPL16-GW7 regulatory module determines grain shape and simultaneously improves rice yield and grain quality. Nat Genet. 2015;47(8): 949-54.

42. Moreno MA, Harper LC, Krueger RW, Dellaporta SL, Freeling M. liguleless 1 encodes a nuclear-localized protein required for induction of ligules and auricles during maize leaf organogenesis. Genes Dev. 1997;1 1(5):616-28.

43. Lee J, Park JJ, Kim SL, Yim J, An G. Mutations in the rice liguleless gene result in a complete loss of the auricle, ligule, and laminar joint. Plant Mol Biol. 2007;65(4):487-99.

44. Ishii T, Numaguchi K, Miura K, Yoshida K, Thanh PT, Htun TM, Yamasaki M, Komeda N, Matsumoto T, Terauchi R, et al. OsLG1 regulates a closed panicle trait in domesticated rice. Nat Genet. 2013;45(4):462-5. 465e461-462

45. Zhu Z, Tan L, Fu Y, Liu F, Cai H, Xie D, Wu F, Wu J, Matsumoto T, Sun C. Genetic control of inflorescence architecture during rice domestication. Nat Commun. 2013;4:2200.

46. Bai F, Reinheimer R, Durantini D, Kellogg EA, Schmidt RJ. TCP transcription factor, BRANCH ANGLE DEFECTIVE 1 (BAD1), is required for normal tassel branch angle formation in maize. Proc Natl Acad Sci U S A. 2012;109(30): 12225-30.

47. Manning K, Tor M, Poole M, Hong Y, Thompson AJ, King GJ, Giovannoni JJ, Seymour GB. A naturally occurring epigenetic mutation in a gene encoding an SBP-box transcription factor inhibits tomato fruit ripening. Nat Genet. 2006;38(8):948-52

48. Vandenbussche M, Chambrier P, Rodriques Bento S, Morel P. Petunia, your next supermodel? Front Plant Sci. 2016;7:72.

49. Preston JC, Jorgensen SA, Orozco R, Hileman LC. Paralogous SQUAMOSA PROMOTER BINDING PROTEIN-LIKE (SPL) genes differentially regulate leaf 
initiation and reproductive phase change in petunia. Planta. 2016;243(2): 429-40.

50. Bombarely A, Moser M, Amrad A, Bao M, Bapaume L, Barry CS, Bliek M, Boersma MR, Borghi L, Bruggmann R, et al. Insight into the evolution of the Solanaceae from the parental genomes of Petunia hybrida. Nat Plants. 2016;2(6):16074

51. Stehmann JR, Lorenz-Lemke AP, Freitas LB, Semir J. The genus petunia. In: Gerats T, Strommer J, editors. Petunia: evolutionary, developmental and physiological genetics. New York: Springer Science \& Business Media; 2008. p. $1-28$

52. Guo Y, Wiegert-Rininger KE, Vallejo VA, Barry CS, Warner RM. Transcriptomeenabled marker discovery and mapping of plastochron-related genes in Petunia spp. BMC Genomics. 2015;16:726.

53. Ning G, Cheng X, Luo P, Liang F, Wang Z, Yu G, Li X, Wang D, Bao M. Hybrid sequencing and map finding (HySeMaFi): optional strategies for extensively deciphering gene splicing and expression in organisms without reference genome. Sci Rep. 2017;7:43793.

54. Li J, Mahajan A, Tsai MD. Ankyrin repeat: a unique motif mediating proteinprotein interactions. Biochemistry. 2006:45(51):15168-78.

55. Zhang SD, Ling LZ, Yi TS. Evolution and divergence of SBP-box genes in land plants. BMC Genomics. 2015:16:787.

56. Shao F, Lu Q, Wilson IW, Qiu D. Genome-wide identification and characterization of the SPL gene family in Ziziphus jujuba. Gene. 2017;627:315-21.

57. Kavas M, Kizildogan AK, Abanoz B. Comparative genome-wide phylogenetic and expression analysis of SBP genes from potato (Solanum tuberosum). Comput Biol Chem. 2017;67:131-40.

58. Guo AY, Zhu QH, Gu X, Ge S, Yang J, Luo J. Genome-wide identification and evolutionary analysis of the plant specific SBP-box transcription factor family. Gene. 2008;418(1-2):1-8.

59. Li S, Liu L, Zhuang X, Yu Y, Liu X, Cui X, Ji L, Pan Z, Cao X, Mo B, et al. MicroRNAs inhibit the translation of target mRNAs on the endoplasmic reticulum in Arabidopsis. Cell. 2013;153(3):562-74.

60. Xie KB, Wu CQ, Xiong LZ. Genomic organization, differential expression, and interaction of SQUAMOSA promoter-binding-like transcription factors and microRNA156 in rice. Plant Physiol. 2006;142(1):280-93.

61. Nagae $M$, Nakata $M$, Takahashi $Y$. Identification of negative cis-acting elements in response to copper in the chloroplastic iron superoxide dismutase gene of the moss Barbula unguiculata. Plant Physiol. 2008;146(4):1687-96.

62. Cho SH, Coruh C, Axtell MJ. miR156 and miR390 regulate tasiRNA accumulation and developmental timing in Physcomitrella patens. Plant Cell. 2012;24(12):4837-49

63. Shikata M, Koyama T, Mitsuda N, Ohme-Takagi M. Arabidopsis SBP-box genes SPL10, SPL11 and SPL2 control morphological change in association with shoot maturation in the reproductive phase. Plant Cell Physiol. 2009;50(12):2133-45.

64. Preston JC, Hileman LC. SQUAMOSA-PROMOTER BINDING PROTEIN 1 initiates flowering in Antirrhinum majus through the activation of meristem identity genes. Plant J. 2010;62(4):704-12.

65. Martin RC, Asahina M, Liu PP, Kristof JR, Coppersmith JL, Pluskota WE, Bassel GW, Goloviznina NA, Nguyen TT, Martinez-Andujar C, et al. The regulation of post-germinative transition from the cotyledon- to vegetative-leaf stages by microRNA-targeted SQUAMOSA PROMOTER-BINDING PROTEIN LIKE 13 in Arabidopsis. Seed Sci Res. 2010;20(2):89-96.

66. Yu ZX, Wang LJ, Zhao B, Shan CM, Zhang YH, Chen DF, Chen XY. Progressive regulation of sesquiterpene biosynthesis in Arabidopsis and patchouli (Pogostemon cablin) by the miR156-targeted SPL transcription factors. Mol Plant. 2015;8(1):98-110.

67. Gou JY, Felippes FF, Liu CJ, Weigel D, Wang JW. Negative regulation of anthocyanin biosynthesis in Arabidopsis by a miR156-targeted SPL transcription factor. Plant Cell. 2011;23(4):1512-22.

68. Yu N, Cai WJ, Wang S, Shan CM, Wang LJ, Chen XY. Temporal control of trichome distribution by microRNA156-targeted SPL genes in Arabidopsis thaliana. Plant Cell. 2010;22(7):2322-35.

69. Williams JS, Der JP, dePamphilis CW, Kao TH. Transcriptome analysis reveals the same $17 \mathrm{~S}$-locus F-box genes in two haplotypes of the selfincompatibility locus of Petunia inflata. Plant Cell. 2014;26(7):2873-88.

70. Villarino GH, Bombarely A, Giovannoni JJ, Scanlon MJ, Mattson NS. Transcriptomic analysis of Petunia hybrida in response to salt stress using high throughput RNA sequencing. PLoS One. 2014;9(4):e94651.

71. Tamura K, Stecher G, Peterson D, Filipski A, Kumar S. MEGA6: molecular evolutionary genetics analysis version 6.0. Mol Biol Evol. 2013;30(12):2725-9.
72. Hu B, Jin J, Guo AY, Zhang H, Luo J, Gao G. GSDS 2.0: an upgraded gene feature visualization server. Bioinformatics. 2015:31(8):1296-7.

73. Marchler-Bauer A, Derbyshire MK, Gonzales NR, Lu S, Chitsaz F, Geer LY, Geer RC, He J, Gwadz M, Hurwitz DI, et al. CDD: NCBI's conserved domain database. Nucleic Acids Res. 2015;43(Database issue):D222-6.

74. Bailey TL, Boden M, Buske FA, Frith M, Grant CE, Clementi L, Ren J, Li WW, Noble WS. MEME SUITE: tools for motif discovery and searching. Nucleic Acids Res. 2009;37(Web Server):W202-8.

75. Dai X, Zhao PX. psRNATarget: a plant small RNA target analysis server. Nucleic Acids Res. 2011;39(Web Server issue):W155-9.

76. Mallona I, Lischewski S, Weiss J, Hause B, Egea-Cortines M. Validation of reference genes for quantitative real-time PCR during leaf and flower development in Petunia hybrida. BMC Plant Biol. 2010;10:4.

77. Livak KJ, Schmittgen TD. Analysis of relative gene expression data using realtime quantitative PCR and the $2^{-\Delta \Delta C T}$ method. Methods. 2001:25(4):402-40.

\section{Submit your next manuscript to BioMed Central and we will help you at every step:}

- We accept pre-submission inquiries

- Our selector tool helps you to find the most relevant journal

- We provide round the clock customer support

- Convenient online submission

- Thorough peer review

- Inclusion in PubMed and all major indexing services

- Maximum visibility for your research

Submit your manuscript at www.biomedcentral.com/submit 